\title{
Implementing an epistemologically authentic approach to student-centered inquiry learning
}

\author{
David T. Brookes 1 \\ Department of Physics, California State University, \\ Chico, 400 W. 1st Street, Chico, California 95929-0202, USA \\ Eugenia Ektina@ \\ Graduate School of Education, Rutgers University, \\ 10 Seminary Place, New Brunswick, New Jersey 08901, USA \\ Gorazd Planinsic (1) \\ Faculty of Mathematics and Physics, University of Ljubljana, \\ Jadranska ulica 19, 1000 Ljubljana, Slovenia
}

(Received 25 June 2019; accepted 13 December 2019; published 4 December 2020)

\begin{abstract}
[This paper is part of the Focused Collection on Curriculum Development: Theory into Design.] This paper discusses the theoretical framework and curriculum materials that form the basis of the Investigative Science Learning Environment (ISLE) approach to learning and teaching physics. ISLE, as a philosophical approach to learning, has two core intentionalities: (i) We want students to learn physics by thinking like physicists; by engaging in knowledge-generating activities that mimic the actual practices of physics and using the reasoning tools that physicists use when constructing and applying knowledge. (ii) The way in which students learn physics should enhance their well being. These intentionalities form the basis upon which we build a bricolage of multiple theoretical perspectives. We will show how the ISLE approach and its implementation is shaped by (a) the epistemological commitments of physics, (b) the findings of cognitive science, (c) theories of learning communities, and (d) the perspective of universal design. We will present both qualitative and quantitative data that demonstrate the effectiveness of ISLE in helping students to achieve our intentionalities. We conclude with a call to curriculum developers and implementers to explicitly articulate their intentionalities and theoretical perspectives so that we may forge deeper connections between educational theories, curriculum development, and implementation.
\end{abstract}

DOI: 10.1103/PhysRevPhysEducRes.16.020148

\section{AN INTRODUCTION TO ISLE}

The Investigative Science Learning Environment (ISLE) is a holistic interactive-engagement approach to learning and teaching physics that has a goal of engaging students in learning physics by following processes similar to those that physicists use while constructing and applying new knowledge. The approach includes all aspects of students learning physics such as constructing, testing and applying new ideas through experimentation and reasoning, solving problems and of class organization including assessment and grading policies. To give the reader a feeling of how students construct a concept in the ISLE environment we start with a quick example of students constructing and applying the concept of wave superposition as a part of the wave motion

Published by the American Physical Society under the terms of the Creative Commons Attribution 4.0 International license. Further distribution of this work must maintain attribution to the author(s) and the published article's title, journal citation, and DOI. unit. We present a concrete example first so that the reader will have an idea of "ISLE in action" before we examine its theoretical underpinnings. The wave superposition unit starts with a question posed to pique students' curiosity: "How do noise canceling headphones work?" Prior to investigating superposition, students first investigate how a single pulse on a Slinky propagates through the Slinky. They come to an understanding of how a pulse can carry energy without translating the medium in the direction of the pulse's motion. Below, we describe the investigative process that students go through to construct the idea of superposition.

Students begin with what we call an observational experiment: Groups of students are asked to create two equal amplitude pulses at opposite ends on the same side of the Slinky, observe and describe what happens when they meet (Fig. 1). They can also observe slow motion videos of the same experiments. After that, the students work in their groups to devise possible explanations for the observed behavior of the pulses.

There are two explanations that commonly emerge from students' discussions. Some students explain the interaction 

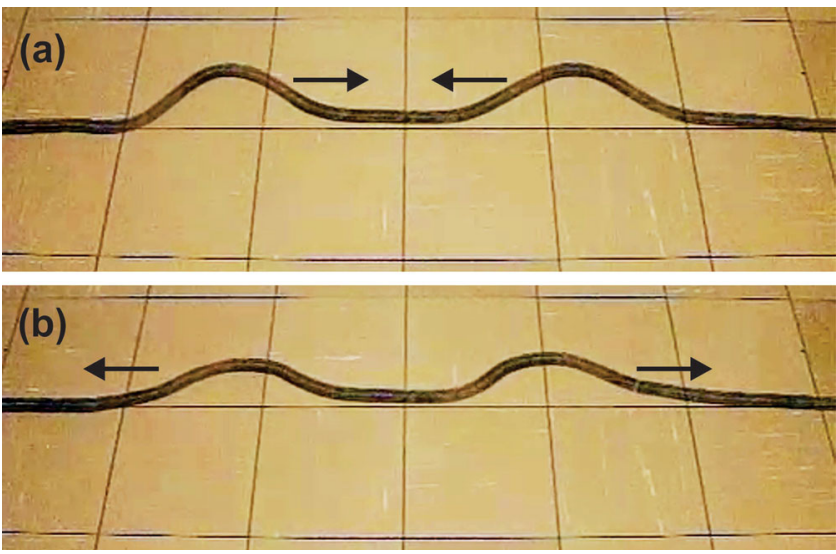

FIG. 1. Observational experiment: Snapshots of the two pulses (a) before and (b) after they meet.

of pulses as collisionlike processes [1] saying that the pulses "bounce off" of each other. The other explanation that students commonly devise is that the pulses "pass through" each other without affecting each other.

To test the two explanations that the students invent, they are asked to propose experiments whose outcomes they can predict using those explanations. These experiments are called testing experiments, they are epistemologically distinct from observational experiments their goal is to answer the question: which of the two proposed hypotheses is correct? Based on many years of experience working with students, we find that the students propose either to send two unequal pulses of the same sign or two equal pulses of the opposite signs towards each other. Let's assume they propose the "two unequal pulses with same sign" experiment. Next, they need to make two predictions for that one experiment, based on the two explanations. These have to be different predictions otherwise the testing experiment will not allow them to distinguish between the two explanations. To represent their predictions students use a representational tool that they learned previouslydisplacement vs position graphs. These graphs are the "snapshots" of the pulse, later expanded into sinusoidal $y(x)$ graphs for traveling waves.

Table I shows the progression of students' thinking while making the predictions for the experiment when two unequal pulses are sent towards each other. The predictions show the snapshots of the pulses at two different clock

TABLE I. Making predictions based on the two explanations for how the two unequal pulses of the same sign will interact.

\begin{tabular}{ll}
\hline \hline Testing experiment: & \multicolumn{2}{c}{ Prediction based on: } \\
\hline $\begin{array}{c}\text { Send two unequal pulses } \\
\text { of the same sign }\end{array}$ & $\begin{array}{c}\text { Bounce-off } \\
\text { explanation }\end{array}$
\end{tabular}
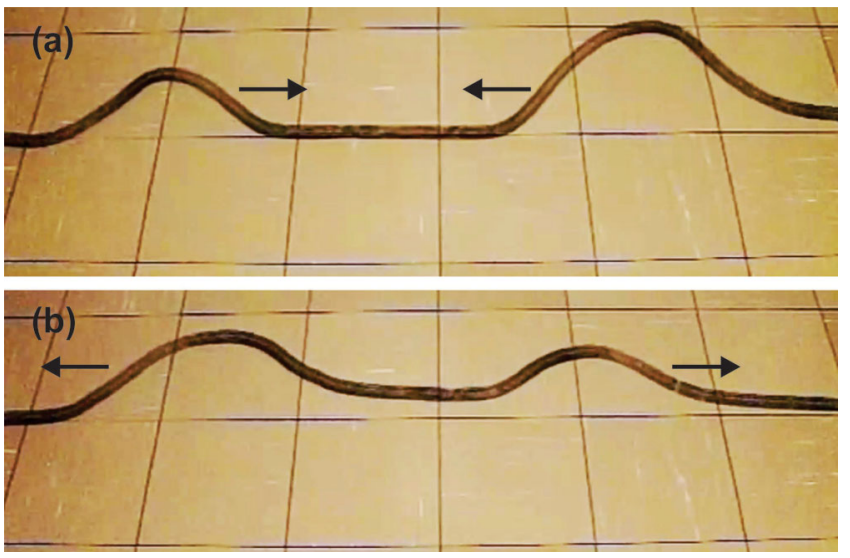

FIG. 2. Outcome of the first testing experiment. Snapshots of the two pulses (a) before and (b) after they meet.

readings - before and after they meet. You can see from the figure that the predictions of the outcome are different for the two different explanations. Once the predictions are made, students conduct the experiments and record the outcome. Later, they can observe slow motion videos of the same experiment (see Ref. [2]) to develop a deeper understanding of how pulses add together.

Figure 2 shows that the outcome of the testing experiment disproves the bounce-off explanation and supports the passthrough explanation. A similar process can be followed if students come up with the experiment to send two equal pulses of the opposite signs towards each other (Fig. 3).

Frequently, when describing the observational experiment, students comment that when the pulses meet for a brief time the amplitude increases. The students can watch the slow motion video of the initial observational experiment again and look for any details that might help them refine the pass-through explanation. At this moment all students will notice that when the pulses overlap the
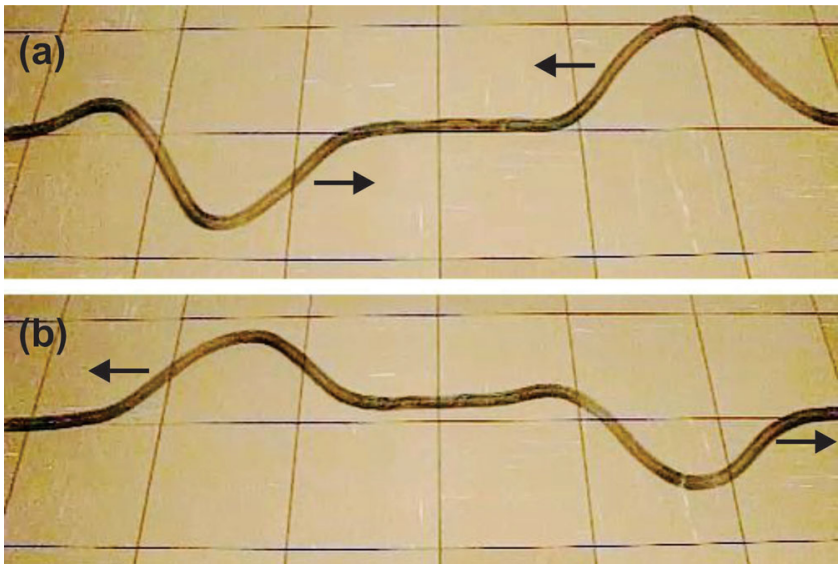

FIG. 3. Outcome of the second testing experiment, sending two opposite-sign pulses towards each other. Snapshots of the two pulses (a) before and (b) after they meet. 


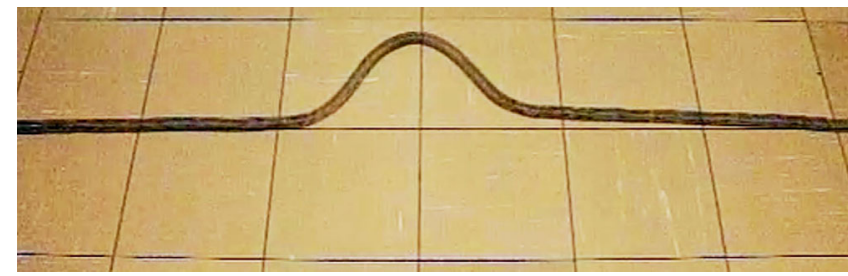

FIG. 4. The students watching the slow motion video of the initial observational experiment will notice that when the pulses overlap the amplitude is about twice as large as the amplitude of individual pulse before they met (compare with Fig. 1).

amplitude is about twice as large as the amplitude of individual pulse before they met (Fig. 4).

This new observation leads to an improved explanation that the displacements of the pulses add to each other while the pulses go through each other. This explanation predicts the outcome of the testing experiment in Fig. 2 too. For the testing experiment in Fig. 3 the revised explanation predicts zero displacement at the meeting location only if the pulses have the same amplitude (Fig. 5). This is an assumption that the students can bring up here.

Once students have a firm grasp of this new concept, the instructor can give it a name: superposition. After this step students return to the noise canceling headphones question and work on explaining how they work. We call this final step of the process application because students are applying their physics knowledge.

From the above example we see that students construct the model of superposition of waves by following a path from observing simple experiments to devising multiple models explaining them using appropriate semiotic resources [3], testing the models and applying them for practical purposes. This sequence represents the underlying epistemic process of the Investigative Science Learning Environment [4]. This process is summarized in Fig. 6.

Although the arrows on the diagram represent a progression of logical steps, at any step one can go back and revisit the previous step or examine the assumptions. The process is by no means linear and prescribed. The most important aspect is the opportunity for the students to reject explanations. Falsifiability is one of the distinguishing

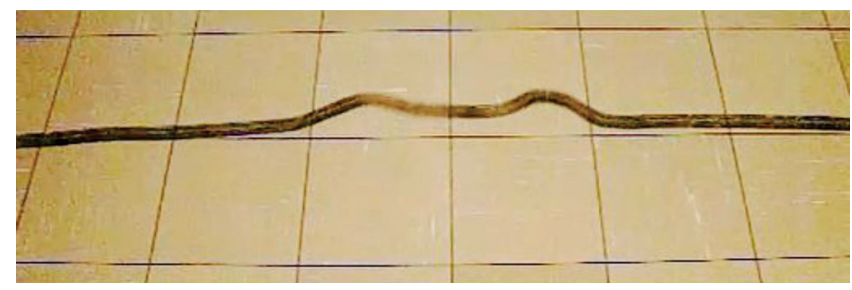

FIG. 5. The outcome of the testing experiment shown in Fig. 3 at the moment when the pulses meet. The displacement at the meeting location is significantly smaller than the amplitudes of the pulses but not zero. Students realize that the prediction included an assumption that the pulses have the same amplitude.

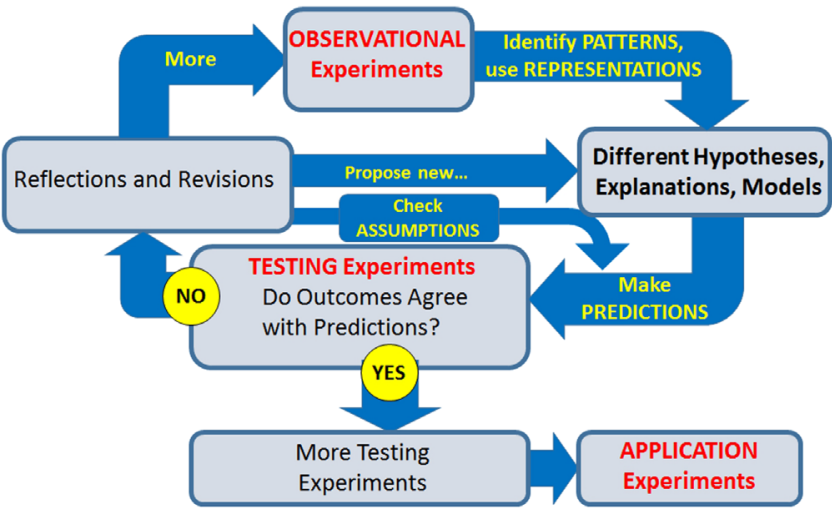

FIG. 6. The underlying epistemic process of ISLE. The process starts on the top of the diagram by students observing and collecting data from simple observational experiments, identifying patterns using appropriate representations, developing explanations or mathematical models, and testing them in testing experiments. The process of testing involves designing the experiment and making the prediction based on the explanation of relation under test and then comparing the outcome to the prediction. In the case of a match, more testing is needed, in the case of a mismatch the process of revisions starts. Any of the experiments can become an observational experiment when an unexpected outcome occurs.

features of science, therefore learning how to disprove something is what makes students participants in authentic science practices. Two other ideas are crucial-the use of different representations and student collaboration during all of the steps of the process. They work in groups, discuss and argue their opinions and solutions and then share their consensus with the rest of the class using white boards.

\section{THEORETICAL FOUNDATIONS OF ISLE}

In the example in Sec. I we showed how students, working collaboratively on experiments and questions carefully selected by the instructor using the ISLE approach, construct a physics concept by examining multiple possibilities and rejecting some of them. Readers will recognize this as an example of inquiry-based learning where students learn by doing and discussing together and discovering, rather than assimilating or acquiring the knowledge of others. But this description does not completely describe what ISLE is. ISLE inhabits a very specific niche, that was intentionally chosen by its creators. In this section we will answer in more detail the question "what is ISLE" by (a) Identifying the two core intentionalities of ISLE [5] and (b) identifying a "bricolage" of theoretical perspectives [6], combined with the findings of educational research that we use to build ISLE from two intentionalities into a systematic approach to learning.

\section{A. The intentionalities of ISLE}

The call for papers for this special issue stressed the need to bridge the gap between education theory and curricular 
design. Our approach to bridging this gap combines the ideas of educational theorists MacMillan and Garrison [5], and Paul Cobb [6]. MacMillan and Garrison argue that teaching is an intentional activity involving beliefs and values, and wherein teachers engage with and strive to change students' beliefs. Cobb suggests that curriculum design should not be based on a single theory: “... rather than adhering to one particular theoretical perspective, we [should] act as bricoleurs by adapting ideas from a range of theoretical sources." (p. 29). Our proposal is simple: If we can clearly articulate the core intentionalities of our (ISLE) approach, we can use those intentionalities as the criteria by which we evaluate the appropriateness and usefulness of particular theoretical perspectives and the resulting curricular design decisions that we make.

The key to understanding the first intentionality of ISLE is that we believe that the product of knowledge (for example, the principle of superposition for waves) cannot and should not be separated from the means by which it came to be known. Postman and Weingartner [7] lamented the artificial separation of knowledge and process of knowing when they argued that "the medium is the message" [8] and,

"he medium is the message implies that the invention of a dichotomy between content and method is both naive and dangerous. It implies that the critical content of any learning experience is the method or process through which the learning occurs." [7] (p. 19.) [our emphasis]

In other words, every classroom can be viewed in terms of students participating in a set of cultural practices from which students may deduce certain "messages" about knowledge and learning [9]. If the students passively listen to the instructor telling them the results of centuries-old physicists' research, passive acceptance of knowledge from authority is the message conveyed by the medium. But also the purely empirical view that "active learning increases student performance in science, engineering, and mathematics" [10] is missing something. Stated as fact ("active learning increases student performance"), it is missing a key question: What is the message that each particular active learning environment in their meta-analysis study is conveying to the participants?

The first intentionality of ISLE is that students should learn physics by engaging in activities that mimic the authentic knowledge-generating activities of practicing physicists. Therefore we see ISLE as an example of "epistemologically authentic" inquiry [11]. Further justification for this choice in terms of the demands of the 21 st century workplace and other factors may be found in Ref. [4]. The point that we wish to make is that this is a value-laden intentional choice that goes beyond empirical science, but need not exclude science from our instructional design choices.

The second intentionality of ISLE, while emerging later in our own theoretical journey, is of equal importance to the first. We came to realize that the first intentionality of ISLE was not enough to facilitate student learning on its own. If we want students to construct knowledge by thinking like physicists, they need to be motivated to engage in the process. They need to feel that they can create knowledge and that this knowledge is meaningful and useful in their lives. We came to realize that dehumanizing mythologies of physics such as the narrative of individual brilliance [12] can create significant motivational barriers for students. The second intentionality of ISLE is that all our choices of theoretical perspectives and our curricular design decisions should enhance or nurture human well being rather than harm it.

\section{B. Theoretical perspectives, a bricolage}

Over $20+$ years of development, we have constructed what we can most accurately refer to as a bricolage of theoretical perspectives that form the basis of the ISLE approach. If the core intentionalities of the ISLE approach are to engage students in the process of doing physics by participating in authentic scientific practices while simultaneously enhancing the well being of our students we need to ask "what are the authentic practices of physics?" while simultaneously look for perspectives and/or approaches that can help us recast some of those activities in ways that enhance our students' well being. Learning physics, and science in general, can be viewed from four primary perspectives that form the basis of our theoretical bricolage.

1. Learning physics is a series of knowledge-generating activities where students as scientists play an intricate but communally well understood set of "epistemic games" [13], involving an interplay experimentation and theory, governed by a set of socially agreed-upon rules of behavior and operation which we will refer to as the epistemological commitments of science. These include specific roles for experimentation and for inductive and hypothetico-deductive reasoning.

2. Learning physics is a cognitive activity: More specifically, "doing physics" entails coordinating multiple representations $[14,15]$ to construct meaning. Modern cognitive science can help us understand the role of representation in human cognition and inform us about how to use a variety of representations to make physics more accessible to learners.

3. Learning physics is a sociocultural activity $[16,17]$ wherein "... the validity of what we do in science rests exclusively in the operational consensuality in which it arises as a manner of human coexistence..." [17] (p. 23). In this perspective, we view students as participants in a community of learners [18], working towards shared goals and transforming their participation over time [19].

4. Learning physics should be an empowering rather an exclusionary activity for students. To realize this, we need to understand and employ theories of human 
interaction and motivation that will promote equity and accessibility.

Below, we expand in detail how these four perspectives are informed by various theoretical frameworks.

\section{Doing physics: Interplay of experiment and theory}

To engage students in the process of doing physics we needed a simplified model of the actual logical progression of the activities of physicists. In early discussions (circa 2000) the developers of ISLE came to the pragmatic conclusion that the centuries-old debate as to whether physics is inductive or hypothetico-deductive [20-22] is unproductive. Physics is both inductive [23] and hypothetico-deductive [21]. As Born [24] pointed out,

"...the theories which they [Galileo and Newton] formed by synthesis of experimental results were used for suggesting new experiments, and if these tests were favourable the theory was considered as confirmed. That is the legitimate method of science, a blending of deduction and induction, which is described in innumerable textbooks." (p. 6)

In looking for a framework to structure classroom activities, we did not search for "the one correct scientific method," instead we asked: What are the fundamental epistemological commitments of scientists, without which science would cease to be regarded as "science?" We have come to the conclusion that scientists build knowledge using empirical, reproducible evidence [25], they use both inductive and hypothetico-deductive reasoning [24], and they value coherent and experimentally testable ideas, which means that these ideas can be rejected by an experiment unlike, for example, religious ideas that cannot [26]. These epistemological commitments and their logical connections form the core of what students $d o$ when they engage in activities in a classroom structured around the ISLE approach. (Throughout the remainder of the paper we will refer to a classroom in which the ISLE approach is implemented as an "ISLE classroom." Students who are learning physics in a classroom that implements the ISLE approach will be referred to as "ISLE students.") Every activity has an identifiable epistemological (knowledgegenerating) purpose. This is summarized in the diagram in Fig. 6. The figure shows that experimentation in physics can be grouped into three categories: observational, testing and application. Modeling and explaining comes between observational and testing. The process of knowledge creation in physics does not start from a hypothesis, it starts with something that needs explaining. While the thing that needs explaining is not always an experimental result, we simplify the process ISLE by starting with an observational experiment.

The symbiotic interplay of experimentation and theory development naturally humanizes the process of doing physics in two ways: (a) Students see how new physics ideas develop naturally from the need to explain something that is currently not understood, dispelling the myth that new ideas can only be created by a few brilliant and creative geniuses. (b) By generating multiple explanations and using those explanations to make predictions for the possible outcomes of a testing experiment (as scientists do), students have less "skin in the game." It is acceptable to propose "wrong" explanations as long as they are consistent with prior experimental evidence. Students do not feel embarrassed when the outcome of the testing experiment does not match a prediction based on their explanation: They learn that ruling out explanations is an integral part of the "game" of science.

\section{Cognitive science perspective: The role of representations}

If anyone reading our paper is thinking that "students don't have 400 years to reinvent all of physics," we agree. If we want students to discover physical ideas, we need to find a way for students to learn efficiently in the time that they are in our physics classes. A cognitive theory or framework of cognitive theories can help us to create effective classroom activities that circumvent many of the cognitive pitfalls that made the development of ideas in physics so protracted and drawn out. Yet at the same time we do not want to take away the authentic experience that students have, authoring their own knowledge and understanding by engaging in authentic scientific practices. We suggest that a productive cognitive framework can be developed if we view physics as a representational activity. Aligned with Airey and Linder [3], we "interpret social semiotics as a broad construct where all communication in a particular social group is viewed as being realized through the use of semiotic resources" (p. 96). It is common for research in the area of physics education that is framed by social semiotics to refer to such semiotic resources as representations. "Doing physics" is an act of coordinating multiple representations [14,15]. Diagrams and pictures [27], equations [28], words [29]; even kinesthetic actions and experiences [30-32], and physical equipment $[33,34]$ are all semiotic resources that can be coordinated in various ways to make sense of the physical world. Requiring students to coordinate multiple representations has been shown experimentally to improve understanding as compared to students who only use a single representation [35]. Below we make a number of points about representations in cognition and then show how they may be connected together into a coherent framework that guides instructional design in Sec. III.

1. When we communicate, we communicate using representations or inscriptions [36]. Communication is at its most fundamental level a negotiation of meaning through a shared repertoire of representations [37]. To explain what this means, we will use the word "force" as an example. In Ref. [38], we 
have discussed how the word force is a part of students' repertoire and physicists' repertoire. Both students and physicists use the word force as part of their daily vocabulary. But when physicists talk about force in the restricted context of physics, the meaning assigned to force refers to a physical quantity characterizing interactions between two objects. In conflict with this, students associate the term force with both kinetic energy and momentum that characterize the motion of individual objects, a carry over from historic and the everyday meanings we associate with the term force. These associations are in conflict and so when the teacher says force, students are not necessarily activating the same meaning as the teacher intends. This problem is fundamental to the nature of all communication according to Reddy [37] and can only be resolved if the instructor and the students communicate back and forth to renegotiate shared meaning, mutually recognizing the distinct contexts in which the word force can activate different associations. This view is also inherently humane, holding both sides accountable in the communication act.

2. Cognition occurs both in the brain and outside of the brain, in the material world [33,34]. The physical and representational tools with which we equip students are more than just useful tools, they are an integral part of human cognition. The tools we give to students directly influence their reasoning. For example, a small whiteboard that students cluster around to share ideas can become an artifact that enables cognition to be moved from the brain of the individual to a shared space and becomes distributed among multiple individuals.

3. The ideas above are undergirded by a modern set of cognitive theories that are in various contexts referred to as "perceptual symbol systems" [39], "embodied cognition," [40] and/or "grounded cognition" [41]. All of these cognitive theories and others like them posit that human cognition occurs within the brain's perceptual and motor systems which are more generally referred to as the modal systems of the brain. What this means is, we think with our motor cortex, with our visual cortex, and so on. Perhaps it is easier to understand this idea by noting that these theories reject the traditional idea that there are separate parts of the brain devoted to abstract semantic and/or mathematical operations. The importance of these theories is that they explain the idea that representation can be extended to any object or action in the physical world that engages one or more of the brain's modal systems and the idea that we think with these representational tools.

4. As a consequence of the points above, we can naturally extend the Sapir-Whorf hypothesis [42-44] to all the representational or semiotic tools students engage with. According to the original hypothesis, the language we speak affects the way we think (in addition to the more common belief that how we think affects how we speak). Therefore representations that students use shape their cognition and can facilitate or inhibit students' thinking depending on how they are designed and used.

\section{Sociocultural perspective: Learning communities}

In the light of the discussion above, it seems natural that, in order to maximize students' cognitive capabilities, we can exploit the phenomenon of collective intelligence [45] by having students work together to achieve shared learning objectives. Researchers have suggested that under the right conditions, the collective intelligence of a group can outstrip the combined intelligences of the individual participants $[46,47]$. How can we create the conditions for collective intelligence to emerge in the classroom? In our experience, we need to do more than simply tell students to work together in groups and hope they will collaborate effectively. We need to help create a learning community in which the collective advancement of knowledge by the class supports the growth of individual knowledge as members participate in that knowledgebuilding community [48]. In different fields of knowledge (education, social psychology, health science, economics, and industry) researchers have found an overlapping set of principles that govern successfully functioning communities of people who work together towards shared goals. We will highlight some of the major areas of overlap below:

1. Communities thrive when resources are equitably shared, distributed, and appropriately managed [49-51]. It is important to note that in a knowledge community, "resource" is not as obvious or well defined as a physical object like oil, or water, or fish. A resource can be a piece of understanding "possessed" by a community member. They can choose to share that understanding or withhold it from others. Equally importantly, the resources that participants bring can shape the learning community [52]. But the instructors have to see these resources or promote an environment in which resources are seen as valuable. This is an issue of social justice [53]. It is up to the instructor to listen to and hear good ideas in unexpected places and bring those to the foreground in the learning community. In doing so, an instructor can help marginalized voices and students see the value of their ideas as well as helping the larger community to see the value of these ideas.

2. To build powerful communities instructors must attend to the context $[51,52]$. "Context" can include the social norms of the classroom, the physical layout of the room, as well as the external stressors 
placed on the participants. The instructor can play a pivotal leadership role in designing the classroom space and the social norms of the community, as well as playing an important support role for students who are struggling because of external life stressors that may be affecting their behavior and functioning in the learning community.

3. In successful communities, participants share a sense of legitimacy or identity and/or participate in activities with clearly delineated boundaries [19,49,51,52]. Identity can be built up or threatened in various ways depending on both the norms of the learning community and the backgrounds of the participants and how those two interact with each other in unanticipated ways $[54,55]$.

4. While the instructor's leadership can make or break a learning community, students' sense of self-direction or self-determination $[49,56]$ is also vitally important to the success of the learning community. Students need to have some control over creating the rules of engagement in the classroom. Students' sense of autonomy or how they perceive the "locus of responsibility" in the classroom can directly impact their motivation, engagement, and orientation towards learning [57].

\section{Human perspective: Motivation and equity}

Combined drop and fail rates in traditional physics courses are typically $30 \%-40 \%$ [58], meaning that roughly every third student taking an introductory course fails to complete it successfully on the first try. Professors often cite lack of math preparation, lack of study skills, lack of motivation or all of them together as the reasons for student lack of success. Students are often sent to remedial courses whose goal is to "fix" whatever is deficient with or missing from their backgrounds. It appears that students' deficiencies are being framed analogously to a physical impairment. But could it be that our courses are not "suited" for all students [59] who have different needs when it comes to learning?

Universal design is a framework that originated in architecture [60]. Instead of asking physically impaired people to adjust to the environment in which they found themselves, the goal was shifted to thinking about how to adjust the environment to be accessible to people with a broader range of physical abilities. This is how entrances to the buildings began to be equipped with ramps and the elevators acquired braille-engraved buttons. Later the same concept was applied to education, leading to the framework of universal design for education (UDE) [61]. The initial emphasis was on using technology to help disabled students access the general education curriculum $[62,63]$. The framework was primarily concerned with adjusting the learning environment to the students with physical impairments. Similarly, students in our physics courses who lack math skills, study skills, motivation, or all of them together, are often viewed as having an impairment. To build a UDE-based physics learning system we need to create opportunities for all students to progress at their own pace to be able to start where they are and to have multiple opportunities to learn the same concept. This way the lack of math skills, study skills, or a specific pace of learning would not be the impairments.

However, no learning system is going to be successful if the students are not motivated to learn [64]. In an inquirybased setting like an ISLE classroom, motivation is critical because students are being challenged to figure stuff out for themselves rather than being told the answer. Studies show that motivation to overcome difficulties and solve challenging problems is related to the person's mindset. If one believes that intellectual abilities are fixed then any difficult problem should be avoided. If one believes that intellectual abilities can grow with time then difficult problems are seen as challenge and an opportunity. Having a growth mindset is one of the main motivational factors for learning as it encourages a person to persevere and overcome difficulties. It is important that both the instructor and the students have a growth mindset. The instructor needs to believe that students can learn and the students need to believe that they can learn if they put effort into the process $[65,66]$.

Research shows that motivation is a complex interaction of personal goals (performance versus mastery), orientation towards learning (ego involvement versus task involvement), and source of motivation (intrinsic versus extrinsic) [57]. For example, Cordova and Lepper [67] showed how motivational manipulations such as embedding learning tasks in a meaningful context and offering some freedom of choice, lead to more intrinsic motivation, deeper task involvement, and better performance on a post-test. Covington and Omelich [68] showed that offering students the opportunity to improve a grade (take a retest) helped them to disconnect their test performance from their beliefs about their abilities. Students did better on motivational measures when they were focused on self-improvement rather than social comparison. The key point we wish to make here is that for a learning environment like ISLE to succeed, the instructor must pay explicit attention to students' motivation and orientation towards learning. A combination of the UDE and growth mindset will allow all students to succeed.

\section{IMPLEMENTATION}

In this section we will show how the theoretical perspectives discussed above play out in the practical design of a single ISLE activity and the ISLE approach as a whole learning system.

\section{A. Micro-analysis of one activity: Exploring the relationship between force and motion}

For students, one of the most challenging ideas of classical physics is that forces exerted on an object can 
cause changes in an object's motion. Below we show how we use the ISLE approach to design a single key activity that students can engage in that will allow them to observe forces and motion and make a connection between forces and changes in motion. The first question that needs to be answered during this design process is where this activity is situated in the epistemological process of physicists' reasoning (Sec. II B 1). Being an act of discovering a relationship, it is an observational experiment. Therefore we do not ask students to make any predictions in this activity. Our activity will engage students in experimentation, recording data, followed by inductive reasoning where they should identify a pattern in their data. That, in turn, progresses to developing a hypothesis that the sum of the forces always points in the same direction as the change in velocity. The activity we created for students to discover the connection between forces and motion is shown in Fig. 7.

The tools of this activity have been specifically chosen because of their particular affordances and constraints. While it is easy to push something and change its motion it is difficult to notice the relationship between force and the change when the pushing tool is heavy and rigid as the tool does not show any changes. A flimsy meter stick behaves differently. Its bend indicates how hard one is pushing. Keeping the bend constant, one can exert a constant force. Therefore when students push a heavy bowling ball with this meter stick over a protracted time interval, they have a physical feeling for the force that they are exerting. The

\begin{tabular}{|c|c|c|}
\hline \multirow[t]{2}{*}{ Observational experiment } & \multicolumn{2}{|c|}{ Analysis } \\
\hline & Motion diagram & Force diagram \\
\hline $\begin{array}{l}\text { Experiment 1. One group member needs } \\
\text { to use both hands to push once but hard on } \\
\text { a bowling ball on smooth floor so it rolls in } \\
\text { a straight line. The second member needs } \\
\text { to count seconds (or use a metronome). } \\
\text { The third group member drops sugar } \\
\text { packets on the floor next to the bowling } \\
\text { ball on every count after it has started } \\
\text { rolling. Then the group records the } \\
\text { locations of the sugar packets. }\end{array}$ & & \\
\hline $\begin{array}{l}\text { Experiment 2. Repeat experiment } 1 \text { only } \\
\text { now the fourth group member needs to } \\
\text { push the moving bowling ball very lightly } \\
\text { in the direction opposite to the direction of } \\
\text { the ball's motion trying to exert a constant } \\
\text { push (it is easier to do if you use a ruler and } \\
\text { keep the same bend). Other group members } \\
\text { repeat the same procedure. The sugar } \\
\text { packets need to be put on the floor after the } \\
\text { ruler touches the ball. }\end{array}$ & & \\
\hline $\begin{array}{l}\text { Experiment 3. Repeat experiment } 1 \text { only } \\
\text { now the first group member needs to } \\
\text { continuously push the bowling ball trying } \\
\text { to exert a constant push (it is easier to do if } \\
\text { you use a ruler and keep the same bend). } \\
\text { Other group members repeat the same } \\
\text { procedure. The sugar packets need to be } \\
\text { put on the floor after the ruler touches the } \\
\text { ball. }\end{array}$ & & \\
\hline $\begin{array}{l}\text { Discuss with your group members the patter } \\
\text { motion diagram and the vector sum of the fo } \\
\text { your forces are labeled with two subscripts. }\end{array}$ & $\begin{array}{l}\text { ns } \\
\text { in the direction of } \\
\text { es exerted on the ba }\end{array}$ & $\begin{array}{l}\vec{V} \text { arrow on the } \\
\text { lake sure that all }\end{array}$ \\
\hline
\end{tabular}

FIG. 7. Activity 3.3.1 from the active learning guide. Observational experiment to find the relationship between the force diagram and motion diagram [69]. smooth surface such as a linoleum-tile floor, effectively approximates a frictionless environment, thus eliminating the most problematic confounding variable from the experiment. These affordances help to make the connection between the force and changes in the ball's motion far more apparent. The kinesthetic experience of exerting the force and physically experiencing the change in motion (students need to push the ball and run with ball, either slowing down or speeding up) adds an additional layer of mental representation (Sec. II B 2). This particular activity is the product of many years of refinement by the creators of ISLE. Many different iterations were tried and shelved. For example, pulling someone on rollerblades using a rope and spring scale can run into problems because (a) instructors do not always have access to a skilled rollerblader, (b) it works only as a whole-class demonstration, limiting the possibility of many students to experience the activity themselves, and (c) slowing the rollerblader down over a long time period is not as easy to do. However there is no one "right way" to do this activity. In certain scenarios (a small class with a skilled rollerblader present) pushing a rollerblader with a bathroom scale against her back can be effective.

A single activity such as this one cannot be viewed in isolation. We need to also think about what representational tools students can use to analyze the given situation. Students need to be proficient in drawing motion diagrams that contain both velocity arrows and arrows that represent the changes in velocity. We also pay careful attention to language. When students are describing the motion of the bowling ball, we ask them to describe it in simple terms ("slowing down," "speeding up," "constant speed"). Additionally, students are introduced to force diagrams through a prior activity where they hold a bowling ball in one hand and a tennis ball in their other hand and are asked to draw two force diagrams side by side, one for the tennis ball and one for the bowling ball. As discussed above in Sec. II B 2, force is a highly problematic concept for students. Therefore we pay careful attention to how we represent forces in force diagrams. We ask students to always use two subscripts to represent the object that is exerting the force and the object that is having a force exerted upon it. For example, the force exerted by Earth on the ball is represented $\vec{F}_{E \text { on } B}$. We ask students to use the length of the force arrow to represent the strength of the interaction. If students attend to the length of the arrows in their force diagram, the diagram can be used to infer which forces are larger than others and identify the direction of the sum of the forces. The example in Fig. 8 highlights the key features and decision-making steps involved in drawing a force diagram. Note that at this stage we strictly stick to the point object model. This way we avoid several complications (in which point in or on the object the force is exerted).

Heller and Reif [70] experimentally demonstrated that it is critically important that students understand all the 


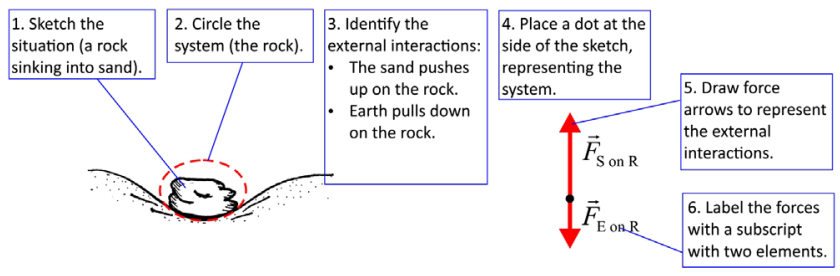

FIG. 8. Steps that the students are supported to follow when drawing a force diagram.

nuances of our (physicists') force model and that the model is fully explicated for students. Why not refer to the force exerted by the hand on the ball as "normal force" and the force exerted by Earth on the ball as "weight" or " $F_{\mathrm{g}}$ ?" The affordances of using two subscripts are that they foreground the interactional nature of force as physicists use the term, and simplify the notational structure in the sense that students do not have to deal with a "menagerie" of named forces (normal force, tension, weight, etc.) [71] (p. 22). This choice of always using two subscripts is an example of a representational choice that may appear cumbersome at first, but where the representational affordances outweigh the constraints. If we want students to reason with a representation, the representation needs to embody its key meanings as explicitly as possible.

Naturally when students are analyzing the forces exerted on the bowling ball that is already moving (after it was pushed), the question comes up "should I put the force that my hand gave it into the force diagram?" From the perspective of "negotiating meaning" this discussion is necessary for students to have. Never have we had success by simply saying to students "this is the meaning of force in physics" and expecting that they will simply adopt this meaning and run with it. Our job is to create the space for this discussion to take place through some sort of whiteboard presentation of their experimental results or sharing ideas between groups. This is where the learning community framework (Sec. II B 3) is important. The instructor can influence the norms and values of the community, welcoming this question. The ISLE approach values students' ideas and intuitions as a natural part of the reasoning process of building scientific ideas and therefore the framework of equity and inclusion (Sec. II B 4) is a necessary part of the thought process of the instructor. If the participants see this discussion as important rather than an irrelevant waste of time, then they will more readily be willing to engage in arguing this out until resolution is reached. Resolution can be difficult here. In our experience, students will fall into two camps: Let us call them "adopters" and "holdouts." Adopters recognize that physicists are using force in a specialized way and argue that since the hand is no longer in contact with the ball, it should not be in the force diagram. The holdouts feel that there must be a way to describe whatever it is that the bowling ball has that makes it hurt when it runs into you or takes a chunk out of the wall (if it runs into a wall). The instructor can respond to this impasse by acknowledging the "holdouts" are quite correct in their intuition, but that their idea is going to be called "momentum," a physical quantity that we would like to keep distinct from force, and we will come back to studying it later in the semester.

\section{B. Building ISLE on multiple theoretical perspectives: Curriculum design and class organization}

The example above as well as the example at the beginning of the paper were individual activities that showed how the theoretical foundations of ISLE are reflected in the curriculum materials. But ISLE is not a curriculum-it is an approach that encompasses all aspects of a student learning physics [72]. This includes activities that the students do in class, class setup, the work they do at home, formative and summative assessments, grading scheme, and many others. Here the organization of the course and the materials used by the students and teachers should be viewed in a holistic way [73].

When designing and revising elements of the ISLE approach (we make revisions and improvements continuously) we use all of the theoretical perspectives discussed above. Therefore we will address them as a whole, rather than individually in this section. As we discuss the practical implementation of those aspects, we will note which perspective is crucial for a specific part of implementation.

\section{Curriculum design}

When designing ISLE-based curriculum materials we are guided by the same questions for every concept:

1. What is the idea (model, mechanism, relation, etc.) that we want our students to construct?

2. What scientific habits of mind (called scientific abilities) do we want them to develop and practice while doing it?

3. What will students do to construct this idea and how will they do it?

4. What evidence will convince us that the students have constructed the idea (model mechanism, relation, etc.)?

These questions might seem common to any backwards designed curriculum materials [74], however the answers to these questions are different in ISLE compared with other approaches.

Specifically, we focus on the following issues: What everyday phenomenon could motivate students to investigate the idea? What simple observational experiments will students observe or conduct? What patterns could they notice? What representations will they use to find the patterns? Do they need extra help with a new representation or what they already know is enough? What explanations, models, or relations will they invent to explain the pattern and what hints will help them to include the crucial explanations? How will they test those explanations? 
What equipment might they need for testing experiments? When they fail to reject one of the explanations or models, how will they combine the new model with other knowledge that they have for practical applications? What practical applications would allow students to connect what they are learning to the real world in a meaningful way? How and what should students do to demonstrate that they learned the concept and mastered the reasoning processes?

ISLE-based curriculum materials come in different forms. We have an algebra-based physics textbook [75] supported by the book of activities for the students (active learning guide [69]) with embedded videos of experiments and the book with recommendations for instructors (instructor guide [76]) as well as freely available internet-based materials [77].

\section{Class organization}

Learning of every concept starts with observational experiments. Observational experiments can be real experiments, videos, photographs, or previously gathered data, etc. Students work in groups on all activities using whiteboards and share their findings with the rest of the class through whiteboard presentations. All students contribute to the descriptions of the observational experiments and possible explanations. The different points of view are necessary for the success of the whole process. Multiple explanations help students to see that everyone is able to devise new physics ideas, avoiding the detrimental "brilliance trap" [12]. We pay careful attention to language both as an issue of clear representation, but also an issue of equity. Technical language can obscure what is actually being observed, resulting in classroom inequity in that some students may not comprehend the technical term in the same way as others. Multiple representations allow an intermediate step between phenomena and mathematics helping those who struggle with math.

The heart of the activities are experiments-observational, testing, or application and their discussions. The instructor can summarize the findings of different groups and provides an overview if necessary after the students share their ideas. This has been called "time for telling" [78].

In order to give experiments the epistemological role that they have in physics, labs need to be integrated into the course and drive the inquiry process. The role of the instructor is to help students make sense of their findings, introduce them to productive representations, and foster the learning community norms. After the development and testing of ideas comes the application part, where students use multiple representations to solve paper-and-pencil and experimental problems. We try as much as possible to create application problems that connect the physics they are learning to the world in a meaningful way. For example, when students have invented and tested a hand rule for magnetic field-current interactions we ask them to build a homopolar motor (a popular YouTube theme) and explain how and why it works.

At home, students read an ISLE-based textbook [75] after they have engaged in experimentation and inquiry during class time. This is opposite to the flipped classroom and directly reflects a distinct theoretical framework. Our primary theoretical lens is that we want to engage students in inquiring about physics by engaging in the authentic practices of physicists. A textbook represents compiled knowledge, the end point of the scientific process and therefore belongs at the end of the learning process for a specific concept. The ISLE textbook discusses the same experiments and contains homework problems, most of which are nontraditional in structure and relate to everyday phenomena.

Assessment focuses as much on the development of scientific reasoning and science processes as on the traditional conceptual understanding and quantitative reasoning [79]. There are two crucial parts to the assessment: the students are familiar with the criteria (introduced through scientific abilities rubrics; to read more about the rubrics see Refs. $[79,80])$ and the students have multiple opportunities to improve their work without being punished for resubmissions. The grades are never curved, students receive their grade based on a point-accumulation system $[81,82]$.

Originally we thought the nature of ISLE itself was motivating for students. They are excited to come up with multiple explanations and an opportunity to test their own ideas (they clap when the outcome of the testing experiment matches their prediction and are visibly satisfied when the outcome rejects one of the explanations as this step shows the real power of their own reasoning). However, for some students the excitement inherent in the ISLE process is not enough. From observing the students and seeing sometimes the lack of the drive in the last 10 years we came up with the necessity of creating the "need to know" [83] before each big unit or even a small concept. In the example at the beginning of the paper the need to know is provided by the question "how do noise canceling headphones work?" This question is posed at the beginning of the exploration of waves and the students answer it after the activities described above. The need to know question is posed at the beginning of the exploration and during the course of a unit students return to answering it several times at the increasingly sophisticated levels, first qualitatively and then quantitatively. It is the driving force behind a sometimes long process that takes a few class periods. The need to know examples come from students' own observations and resulting questions (how does the GPS predict the time of travel?), a "cool" video from YouTube (for circular motion we use the video of Damien Walters running a loop-the-loop [84]), or other resources [69].

In addition, the cognitively demanding nature of the ISLE process can cause student frustration at times. Some of them crave teacher authority and feel uncomfortable not 
knowing for a while what the "correct" answer is. Encountering this frustration over the years we designed an "expertise activity" [73], which engages the students in thinking what learning processes they go through when developing expertise in something that they enjoy doing on their own (computer games, music, sports, gardening, cooking, etc.) We ask them to form groups based on their interests and collectively come up with a learning process that they use to learn and improve. Surprisingly, most groups come up with motivation to learn, trying on their own, reflecting on mistakes, receiving feedback from experts, and trying again. These are the steps very similar to the ISLE learning process. Pointing this out and creating the feeling that they are all experts in something and know how to learn improves motivation and encourages the students to persevere.

Using everyday apparatus and continuously relating what they are learning to their everyday experiences, using interesting problems and interesting experiments shows students that the fundamental basic ideas can be learned with elementary, everyday, and cheap materials. We frequently hear the following comment, "I see physics everywhere." As one of our students said: "I was running after the bus in the morning and I felt my chemical energy being converted into kinetic and thermal, I was just thinking while running-here it goes..."

ISLE instructors offer students opportunities to improve their work, which also promotes growth mindset. The fact that the course structure encourages students to improve and resubmit their work without punishment sends a very strong message: Everyone can learn physics and taking more time to do it is not the fault of the learner. This aspect of ISLE-based classrooms connects ISLE vision to universal design. We will elaborate more on how this is achieved in Sec. III B 3 below.

Finally, different instructors have different interests and strengths. Some are interested in using phone apps, some are good video recorders, some have content interests: biology, astrophysics, etc. These interests makes them choose different needs to know and different applications. ISLE is a flexible approach that focuses on building on the strengths of not only students but instructors too.

The best setup for ISLE classes is studio format or a small class where the instructor can use time flexibly moving between experiments, group discussions, and whole class discussions [73]. However, the flexible nature of the ISLE approach allows it to be implemented in larger enrollment courses where labs are coordinated with lectures [85] and problem-solving recitations or only in labs [86].

\section{Assessment}

We have discussed the learning goals of ISLE, and the core design principles that allow us to achieve those goals. In this section we will discuss assessment in ISLE. Since the focus of ISLE is on doing physics, assessment in ISLE needs to be able to (a) assess the process of doing physics, and (b) provide students with opportunities for improvement. Point (a) is self-evident if we accept the idea that learning goals and assessment should be aligned with each other [74]. Point (b) is aligned with the nature of a scientific learning community where revision is a natural and essential part of the process, and aligned with the educational concept of formative assessment. Formative assessment happens when the instructor uses assessment during the learning process to provide students with feedback and a pathway to improvement, while simultaneously using students' successes or failures to adjust instruction. Black and Wiliam [87] showed that the learning gains from systematic attention to formative assessment, particularly self-assessment, are larger than gains found for most other educational interventions. It is also important to understand that a scientific community relies almost completely on formative assessment and formative self-assessment to function successfully and thus the concept is a natural fit with ISLE. To make assessment more process oriented and more formative we have made the following changes to how we assess ISLE students.

Redesigning assessments to match learning goals.-We have changed the types of questions we ask and the way we ask them. Our logic is simple: If we want students to develop and improve certain scientific reasoning abilities, we need to ask questions that directly engage those scientific abilities, thereby aligning goals with assessment. Tables II and III present two examples.

These examples and the reasoning processes they target are part of a broader set of scientific reasoning abilities that we have identified as being at the core of the ISLE approach. These abilities include an ability to represent information in multiple ways, an ability to design experiments to test ideas, an ability to collect and analyze data, an ability to evaluate somebody else's reasoning, etc. These abilities are codified in a set of scientific abilities rubrics that were developed and research-validated at Rutgers University by the ISLE research group circa 2004-2006 [79].

TABLE II. An example of a problem that engages the ability to evaluate a result.

\begin{tabular}{l} 
Rebecca is trying to solve the following \\
physics problem: In the figure, a \\
person pushes two boxes along a \\
smooth frictionless floor. The person \\
exerts a force of $240 \mathrm{~N}$ on box 1. Box 1 \\
has a mass of $50 \mathrm{~kg}$, box 2 has a mass \\
of $30 \mathrm{~kg}$. The system speeds up at a rate \\
of $3.0 \mathrm{~m} / \mathrm{s}^{2}$. Find the force that box 1 \\
exerts on box 2 . Rebecca comes up \\
with an answer: $F_{1}$ on $2=240 \mathrm{~N}$. \\
WITHOUT solving the problem, is Rebecca's answer reasonable \\
or not? Use your knowledge of physics to construct a clear \\
argument why her answer is reasonable or not reasonable. \\
\hline \hline
\end{tabular}


TABLE III. An example of a problem that engages the ability to represent information in multiple ways.

Examine the velocity-versus time graph for an object moving in a straight line.

a. Draw a picture with a coordinate system and make up a story about the motion of an object that is consistent with the $v$ versus $t$ graph.

Explain how your picture and story are consistent with the graph.

b. Find the displacement of the object from 0 seconds to 7 seconds. Explain your reasoning.

The complete rubrics are available in Ref. [88]. While these rubrics were originally developed for students to use in labs to guide and assess their experimental investigations, we have repurposed the same rubrics for homework and exam questions as we show in the example below. Additionally, having a codified set of scientific abilities rubrics facilitated our process of creating assessment questions. Now, when we design exam or homework questions we start from the internal query: "What scientific abilities or clusters of scientific abilities will students need to use to answer this question?" In addition, asking this question has transformed our approach to assessment design [89].

Practical implementation of formative assessment.-The challenge of implementing formative assessment is that it is nice in theory, but takes a potentially massive amount of time investment by the instructor. Over the years we have experimented with different approaches to implementing formative assessment. Scientific abilities rubrics and the feedback that they provide are a natural starting point for allowing multiple attempts or opportunities for improvement in contexts such as lab, homework, and exams.

In the following implementation example, a student answers an exam question. If she is not satisfied with her grade, she may attempt a second, equivalent version of the question at a later time. If she improves, her second grade replaces the first. In Figs. 9 and 10 we show an example of work of a student who attempted an exam question based on a particularly challenging cluster of scientific abilities involving representing forces, evaluating an argument, and conceptually understanding the connection between force and motion. In this example, you can see in the first attempt (Fig. 9), the student had difficulty identifying and labeling the forces exerted on the elevator by other objects. Her evaluation statement explaining why Joe is wrong, while correct, amounts to a repeat of Maria's statement without further elaboration about the underlying connection
PHYS 202A, Exam 1, Version 1, CORE

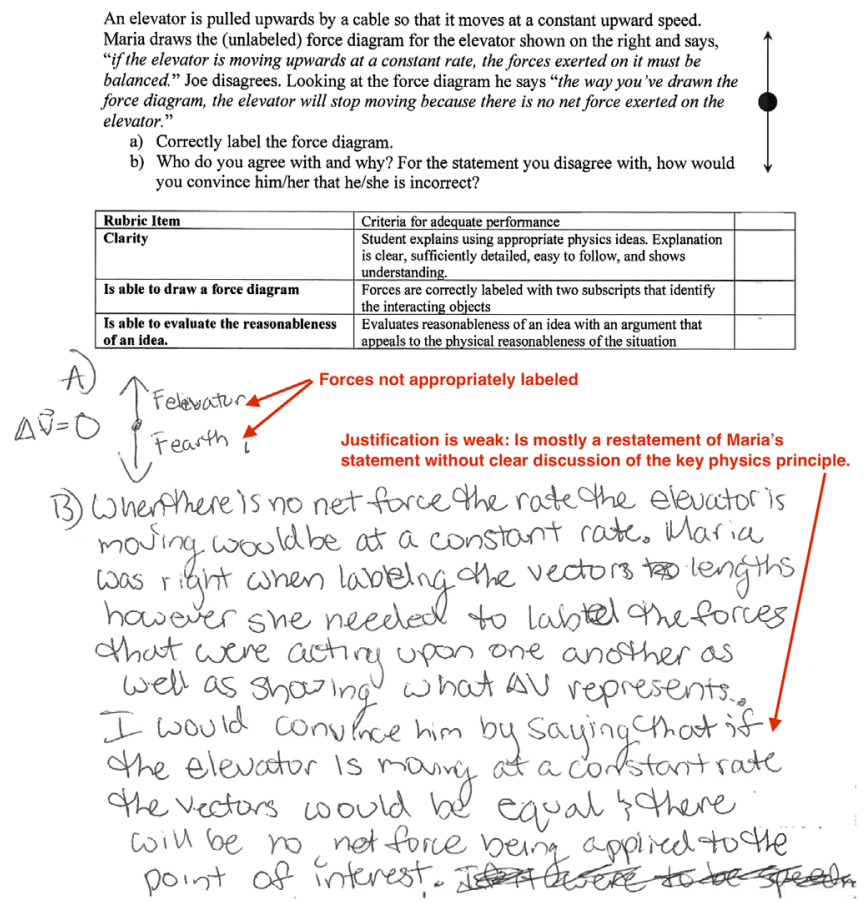

FIG. 9. Student's first attempt at force and motion and evaluation scientific abilities cluster.

between force and motion (namely, that a net force will cause changes in motion). In a second attempt (Fig. 10), the forces are clearly labeled with double subscripts, and the evaluation clearly shows deeper understanding because

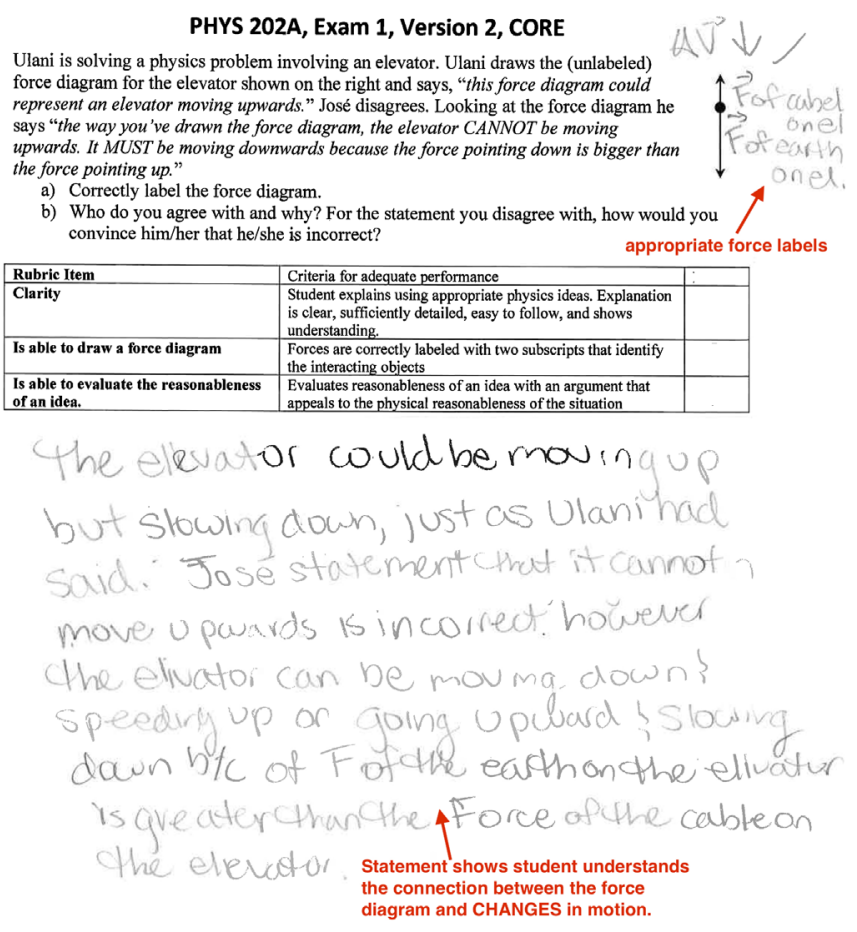

FIG. 10. Student's 2nd attempt at force and motion and evaluation scientific abilities cluster. 
the student recognizes that the force diagram could represent either moving up and slowing down or going down and speeding up. This is an elaboration beyond repeating Ulani's statement, which suggests deeper understanding.

Evaluating student performance can be achieved in different ways. You could score each scientific ability above on a $0,1,2$ scale where $0=$ "missing or inadequate", $1=$ "needs improvement", and $2=$ "adequate". A simpler 0,1 scale could be implemented with $0=$ "inadequate" and 1 = "adequate". The key underlying criterion of an assessment system consistent with the theoretical foundation above is that students' grades are based on a point accumulation system. Results of the exams are never curved and students can accumulate points (if necessary, through multiple attempts or redos) towards their desired final grade. Students' success should depend only on their personal effort and not on the success or failure of other students [82].

In Table IV, we summarize how the important features of ISLE activities, curriculum design, and class organization related to the theoretical perspectives in the previous section.

\section{STUDENTS' EXPERIENCES WITH LEARNING PHYSICS THROUGH THE ISLE APPROACH}

We have shown over many years that ISLE students learn normative physics concepts, can solve traditional physics problems, and are able to design and interpret experiments in the new domains as well as or better than traditionally taught students $[72,85,90]$. But how do they feel about learning physics in a course that implements all of the elements of the ISLE approach? To answer this question we conducted semistructured interviews of students in an ISLE-based studio format course. This course was a two-semester calculus-based physics course taught in a southeastern state university, where the student body was about $67 \%$ Hispanic, $12 \%$ Black, and 10\% White. The median family income of a student was $\$ 57,300$. Many students were the first in their family to attend college. The students in the course where we conducted the interviews were representative of these demographics. There were 31 students in the first year and 30 in the second year of the study. Note that in each year, one student dropped out of the class between the fall and spring semesters. Unless otherwise stated, the outcomes and statistics reported represent the students in the second semester of the course. This course, taught by DTB, represented an attempt by the author to implement all the aspects of the theoretical perspectives and intentionalities of the ISLE approach laid out in Sec. II. This included students engaging in cognitively well-designed activities that followed the logical progression of the ISLE inquiry process shown in Fig. 6, students working collaboratively on these activities and inventing and using an array of multiple representations, actively helping students build a stronger learning community, and careful design and redesign of assessments (including opportunities to redo and improve work) to match the course goals of encouraging deep learning, building community, and developing scientific reasoning abilities, and explicitly discussing and addressing students' conceptions of what it means to "learn" and "understand" something. Various aspects of how we designed the course and course activities are discussed in Refs. [73,89,91,92]. These elements match the four theoretical perspectives of the ISLE learning system discussed in Sec. II B.

The interviews spanned $2 \mathrm{yr}$ and involved 17 students (9 female and 8 male students) out of 61 who took the course during those two years. Out of the 61 students, 37 received an A, 21 received a $\mathrm{B}$ and 3 received a $\mathrm{C}$. The interviewees were selected to represent a wide range of students - those who excelled in the course (10 received an A) and those who did not do so well (7 received a B). The average course grade of the interview group was $87 \%$ while the class average was $86 \%$. The interviews lasted from 21 to $76 \mathrm{~min}$ with an average of $41 \mathrm{~min}$. The questions asked were general and the interviewer often encouraged the interviewees to elaborate on their answers. Examples of the questions are as follows: Did you take a physics class before? If yes, what was it like? Why did you take this class? How does this physics class compare to other science classes you are taking? Would you like to change anything in how this class is taught?

Examples of elaborations questions are as follows: What do you mean? Can you be more specific? Can you give an example?

The interviews were audio recorded and transcribed verbatim. After the full transcript was available, coder 1 (one of the authors) read through it and coded students' statements for themes. The same theme (value of group work for example) would come up several times in the same interview, and was given a number (for example student 1 mentioned a particular theme 6 times). Coder 2 (another author) went through the themes identified by the first coder and either agreed or disagreed with those, adding new themes where appropriate. Finally, the process was repeated with coder 3 . We found that coders 2 and 3 did not add any new themes and agreed with the themes identified with the coder 1 almost $100 \%$ of the time. We then removed all themes related to the discussion of other courses and only focused on the themes related to the ISLE course (the themes are listed later). Figure 11 shows the total number of coded themes per interviewee (broken by gender) and the number of coded statements per $1 \mathrm{~min}$ of the interview. We see that the themes related to the theoretical foundations of the ISLE approach emerged on average with a rate of about 2 themes per 3 min of the interviews and not less than 1 theme per 3 min.

To identify the most common themes we counted in how many interviews the theme was mentioned, independently 
TABLE IV. Elements of the theoretical foundation determine the structure of ISLE activities and class organization.

\begin{tabular}{|c|c|c|}
\hline & Theoretical perspectives of the ISLE approach & $\begin{array}{l}\text { Implementation of the ISLE approach as } \\
\text { determined by theoretical perspectives }\end{array}$ \\
\hline \multirow[t]{3}{*}{ Doing physics } & $\begin{array}{l}\text { a. Students should practice physics when } \\
\text { learning physics. Physicists build knowledge } \\
\text { based on empirical evidence combined with } \\
\text { theoretical reasoning, such as inductive and } \\
\text { hypothetico-deductive. Ideas need to be } \\
\text { coherent and testable. }\end{array}$ & $\begin{array}{l}\text { a. Students construct new knowledge working } \\
\text { first on specially designed activities not by } \\
\text { reading the book. Students develop their ideas } \\
\text { while explaining carefully selected } \\
\text { observational experiments and testing their } \\
\text { explanations using new experiments, thus } \\
\text { mirroring activities of physicists when they } \\
\text { construct and apply knowledge. students" } \\
\text { experience is epistemologically authentic- } \\
\text { they are "doing physics" at every step. }\end{array}$ \\
\hline & $\begin{array}{l}\text { b. Activities in physics and learning physics } \\
\text { serve specific epistemological purposes. } \\
\text { Experimentation can be grouped into three } \\
\text { categories: observational, testing, and } \\
\text { application. Theorizing and modeling } \\
\text { happens between the observational and } \\
\text { testing phases. }\end{array}$ & $\begin{array}{l}\text { b. There are no demos or verification experiments } \\
\text { in an ISLE classroom. Every experiment that } \\
\text { students perform belongs to one of the three } \\
\text { categories. The epistemological role of } \\
\text { experiments is highlighted in all curriculum } \\
\text { materials and activities. Students identify } \\
\text { patterns and build explanatory models, based } \\
\text { on the results of observational experiments. }\end{array}$ \\
\hline & $\begin{array}{l}\text { c. Qualitative and quantitative models should be } \\
\text { consistent with accepted models and agree } \\
\text { with existing and new experimental evidence. } \\
\text { In some cases, testing means agreement with } \\
\text { existing data. }\end{array}$ & $\begin{array}{l}\text { c. No ideas proposed by the students are right or } \\
\text { wrong, as long as they explain experimental } \\
\text { evidence and are experimentally testable. Ideas } \\
\text { that fail to be disproved experimentally are } \\
\text { accepted. }\end{array}$ \\
\hline \multirow[t]{3}{*}{$\begin{array}{l}\text { Cognition and } \\
\text { representations }\end{array}$} & $\begin{array}{l}\text { a. The act of doing physics is an act of } \\
\text { coordinating and combining multiple } \\
\text { representations. }\end{array}$ & $\begin{array}{l}\text { a. Representational practices are naturally } \\
\text { integrated into learning of the normative } \\
\text { content. Representing ideas in multiple ways is } \\
\text { the key to the development of students' own } \\
\text { physics knowledge. }\end{array}$ \\
\hline & $\begin{array}{l}\text { b. Representations used can facilitate or hinder } \\
\text { the learning process. }\end{array}$ & $\begin{array}{l}\text { b. Representations have varying degrees of } \\
\text { abstraction. Specially designed activities help } \\
\text { students progress from less abstract } \\
\text { representations to more abstract } \\
\text { representations. }\end{array}$ \\
\hline & c. Representations involve both mind and body & $\begin{array}{l}\text { c. Students develop and use representations } \\
\text { collaboratively. Activities include kinesthetic } \\
\text { activities in addition to graphical } \\
\text { representations and mathematics. }\end{array}$ \\
\hline \multirow[t]{3}{*}{$\begin{array}{l}\text { Learning } \\
\text { community }\end{array}$} & $\begin{array}{l}\text { a. Every member of the community can make } \\
\text { valuable contributions to the learning } \\
\text { process. }\end{array}$ & $\begin{array}{l}\text { a. Students collaborate developing ideas in class. } \\
\text { Everyone contributes when looking for } \\
\text { patterns in observational experiments } \\
\text { proposing explanations and testing them or } \\
\text { using representations to solve problems. }\end{array}$ \\
\hline & $\begin{array}{l}\text { b. Context, physical space, and external } \\
\text { stressors are important for the life of the } \\
\text { community. }\end{array}$ & $\begin{array}{l}\text { b. The instructor does not validate student ideas, } \\
\text { the experiments do. Students share their ideas } \\
\text { with each other using small whiteboards and } \\
\text { whole class discussions when the groups } \\
\text { present their findings. The instructor } \\
\text { synthesizes and summarizes the emerged ideas } \\
\text { at the end in the form of "time for telling." }\end{array}$ \\
\hline & $\begin{array}{l}\text { c. The success of the community depends on the } \\
\text { opportunities of the members to control what } \\
\text { is happening in the community and on their } \\
\text { sense of belonging. }\end{array}$ & $\begin{array}{l}\text { c. Students help each other to design their own } \\
\text { experiments, interpret data, and solve } \\
\text { problems. As there is no "curve" the success of } \\
\text { one student does not hinder the success of } \\
\text { others. }\end{array}$ \\
\hline
\end{tabular}


TABLE IV. (Continued)

\begin{tabular}{|c|c|c|}
\hline & Theoretical perspectives of the ISLE approach & $\begin{array}{l}\text { Implementation of the ISLE approach as } \\
\text { determined by theoretical perspectives }\end{array}$ \\
\hline \multirow[t]{2}{*}{$\begin{array}{l}\text { Motivation and } \\
\text { equity }\end{array}$} & $\begin{array}{l}\text { a. Development of growth mindset is an } \\
\text { important aspect of motivation. }\end{array}$ & $\begin{array}{l}\text { a. Students are not made to feel unsuccessful by } \\
\text { putting their intuition to the test (for example } \\
\text { by asking to make predictions before } \\
\text { observation experiments). Students are asked } \\
\text { to make predictions only when they can be } \\
\text { based on the existing knowledge or on the } \\
\text { explanations under test. Students learn how } \\
\text { testing ideas in physics is similar to testing } \\
\text { them in real life. Scientific abilities rubrics act } \\
\text { as scaffolding. }\end{array}$ \\
\hline & $\begin{array}{l}\text { b. Universal design for education (UDE) means } \\
\text { creating opportunities for all students to be } \\
\text { able to start where they are, to progress at } \\
\text { their own pace, and to have multiple } \\
\text { opportunities to learn the same concept. This } \\
\text { way the lack of math skills, study skills, or a } \\
\text { specific pace of learning would not be the } \\
\text { impairments. } \\
\text { c. Combination of UDE and growth mindset } \\
\text { allows all students to succeed. }\end{array}$ & $\begin{array}{l}\text { b. Previous learning experiences or math skills are } \\
\text { not impediments as new topics start with } \\
\text { observing simple experiments and describing } \\
\text { them in simple words. Multiple representations } \\
\text { help those who struggle with algebra. Reading } \\
\text { the book after the students have struggled and } \\
\text { constructed their own ideas based on physical } \\
\text { experiences empowers them as learners. } \\
\text { c. Students have an opportunity and are } \\
\text { encouraged to revise their work without being } \\
\text { punished for revisions by getting a lower grade. } \\
\text { Guidance is provided through scientific } \\
\text { abilities rubrics that encourage self-assessment } \\
\text { and improvement. }\end{array}$ \\
\hline
\end{tabular}

of how many times it was mentioned in a particular interview (if one person talked about group work 5 times in the interview and another person talked 3 times, both interviews were coded as having the group work theme). The first group of themes (see Fig. 12), mentioned by more than $70 \%$ of the interviewees, were

1. Transfer (mentioned in $100 \%$ of the interviews, mentioned 65 times in total). The code "transfer" was used when the students talked about how they applied physics knowledge, physics representations, physics reasoning skills, and learning strategies they

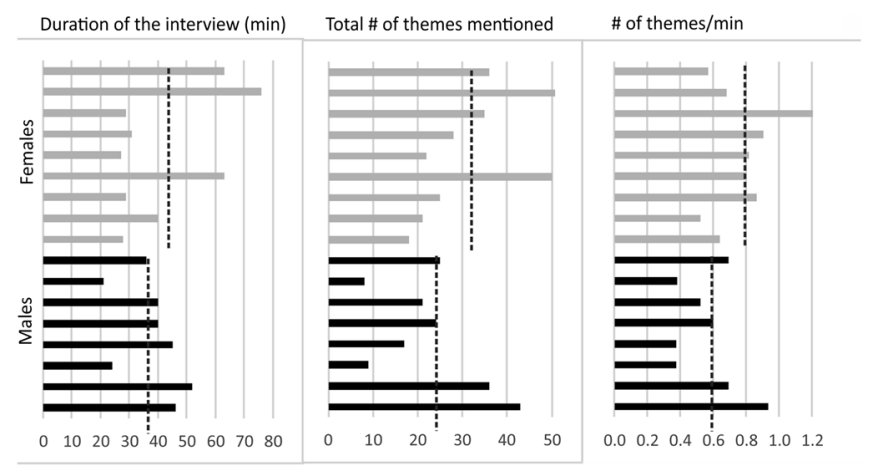

FIG. 11. Duration of the interview, the number of themes, and time frequency coded for each interviewee. Dashed lines show average values. developed in the course in other contexts such as outside world and other courses. We grouped all these comments together as they showed the usefulness of the course, as seen by the students, to different aspects of their lives.

2. Experiments (82\% of interviews, 41 times). Students mentioned the value of learning from experimentation.

3. Affect (76\%, 58 times). Students expressed positive feelings and an emotional relationship with physics.

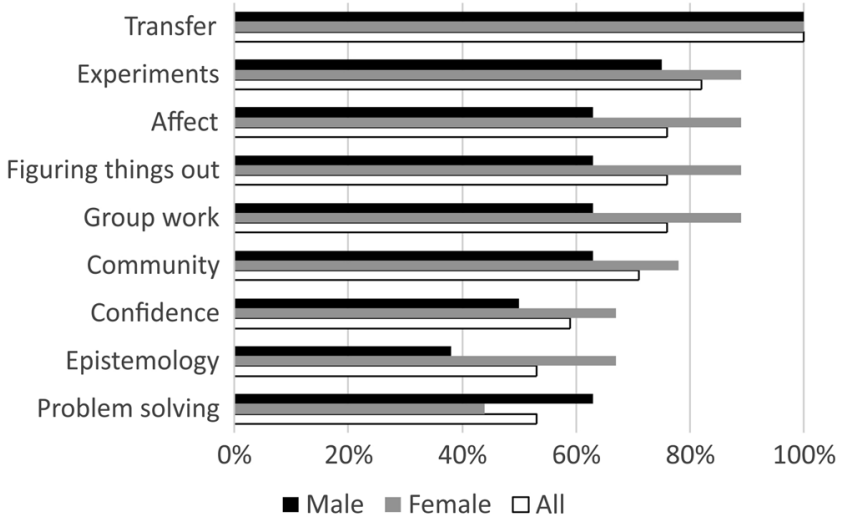

FIG. 12. Most common themes that emerged from the interview broken down by gender. 
4. Figuring things out (76\% of interviews, 48 times). Students talked about the value of opportunities to figure things on their own before being told.

5. Group work (76\%, 44 times). Students mentioned the value and benefit of working together.

6. Community $(71 \%, 26$ times). Students talked about a sense of community in the course.

The next group of themes mentioned in over $50 \%$ of the interviews were

1. Confidence (59\%, 23 times). Students talked about developing a sense of confidence to do physics and solve problems.

2. Epistemology (53\%, 23 times). Students talked about knowing where knowledge and understanding come from.

3. Problem solving (53\%, 21 times). Students talked about their ability to solve problems.

Figure 12 presents all the themes that occurred in more than $50 \%$ of the interviews and shows the percentage of male and female students who mentioned them.

It is interesting that female and male students demonstrated differences related to the most common themes. These themes (with the exception of problem solving and transfer) appeared in a higher percentage of female students' interviews compared to male students' interviews.

There were only a few other themes that more male students mentioned compared to female students. We found male students talked about the increase in their motivation (38\%) while none of the female students mentioned it, the same is true for mathematics (13\% vs $0 \%$ ) and modeling (25\% vs $0 \%)$.

There were other significant themes that were mentioned in less than $50 \%$ of the interviews:

1. the helpful role of homework ( $41 \%$ average, $44 \%$ for females and $38 \%$ for males),

2. having courage to appear incompetent in class $(41 \%$ average, $67 \%$ for females and $13 \%$ for males) and

3 . having confidence to ask questions (29\% average, $33 \%$ females, $25 \%$ males).

Table $\mathrm{V}$ shows examples of theme-coded statements for most common themes.

Do students' responses to these interview questions triangulate with other data sources? In fall of the second year of the study, we administered the Colorado learning attitudes about science survey (CLASS) [93] (pre and post) to the class. We report the data for 26 students who completed both the pre and post test (Table VI). Five data points were discarded because of no post-test. Because of small sample size, readers may be concerned that the 5 lost data points distorted the data. However, we do not think so, because the course grades of the missing students were A, $\mathrm{A}, \mathrm{B}+, \mathrm{C}+$, and $\mathrm{C}-$ representative of the grade distribution of the whole class. We can compare these gains to the CLASS gains reported by Brewe et al. [94] who conducted their Modeling Instruction class in conditions similar to ours. The highest reported gains for Modeling Instruction show an overall positive shift of 9 points with the effect size of 0.71 . The data for the class in this study show an overall positive shift of 16 points with the effect size of 1.06.

Are students' responses consistent with the theoretical perspectives of ISLE? Summarizing the interview themes we can say that they students indeed appreciated all 4 perspectives. They were clear on the epistemological role of the activities they engaged in, they valued the methods of problem solving and the benefits of the group work and being a member of the community. Most importantly, they developed positive affect towards physics and confidence that they can do it. The latter can be related to the growth mindset and the former to motivation. The most common theme, called transfer, can be also explained by increased motivation. We are motivated to do something that we are good at and that is useful. The students indicated that their perception of physics learning in the ISLE environment helped them feel both. We did not do this study to compare male and female students. However, as we started data analysis, the differences appeared and we wanted to present them to the reader. While studies find that the female students have less appreciation and interest in physics than male students [95], this study shows that while all students in our study value what ISLE-based learning provides, the female students appreciated specific elements of the ISLE approach slightly more than males. As this was only a limited study with a few participants, we need to repeat it with a larger audience to be able to make more confident statements about this aspect of our findings.

\section{DISCUSSION}

\section{A. The importance of intentionality in making theoretical choices}

In our paper we have tried to show how the ISLE approach, beginning with two intentionalities, has incorporated multiple theoretical perspectives, which in turn inform the design of classroom activities and momentby-moment decisions in the classroom.

Why is it so important to have an intentional approach to curriculum design? It is our (admittedly biased) observation that change in education in general and physics education in particular has been rather fragmented and slow. Postman and Weingartner [7] laid out a clear set of principles for inquiry-based learning in the $1960 \mathrm{~s}$, yet few of them have been widely adopted. More generally, it is difficult to find examples of effective implementation of educational theory at a classroom level. We suggest the problem is that educators and education researchers have neglected the intentionality of teaching. To reprise the words of Macmillan and Garrison: Teaching is an intentional activity in which we strive to change students' attitudes and beliefs, not simply an act of passing on a body of knowledge and skills. When researchers make recommendations for how to 
TABLE V. Themes with examples for student interviews.

\begin{tabular}{|c|c|}
\hline Theme & Example \\
\hline Transfer & $\begin{array}{l}\text { So even if I'm in a class where the professors like a robot, just talking, reading, Power Points, I can go home and } \\
\text { turn it into something that's going to be interesting to me, because you guys made us think about how we } \\
\text { learned and what the best way to learn is, whereas most students who didn't go through that would probably } \\
\text { just be satisfied reviewing notes because they think that's the best thing to do because they never really taught } \\
\text { about, well maybe I've different, maybe everyone's unique and everyone has a special way to learn. Maybe } \\
\text { I need to utilize what characteristics make me different and then I'll learn better. }\end{array}$ \\
\hline Experiments & $\begin{array}{l}\text { But the way that we learn these things, it's not as hard as what the regular physics students. They're like, oh, my } \\
\text { God, this equation is so difficult to derive and this and that. But our class, we're like, well, it's easy because if } \\
\text { you grasp this and you think about the situation when you get this, and it's cool because we got to do all those } \\
\text { experiments that we understand already how it works. Other students, they memorize and they're like, I still } \\
\text { don't remember how I got that. }\end{array}$ \\
\hline Figuring things out & $\begin{array}{l}\text { It was a learning process because I was so used to be fed information and remembering it and repeating it that } \\
\text { here at the beginning I didn't like it because I was not shared information. I said, what the heck is this, how am } \\
\text { I supposed to learn anything, the professor didn't tell me anything. And I was so used-you're so accustomed } \\
\text { to being fed all this information and memorizing it that you have no idea what's going on. Here I have to figure } \\
\text { out what was going on, and then a true understanding could arise. }\end{array}$ \\
\hline Affect & $\begin{array}{l}\text { I definitely do enjoy physics. I enjoy biology for other reasons but it's just because I love animals so it's a } \\
\text { different reason. But in terms of interaction and stuff like that, I like physics a lot, a lot. And it really does-at } \\
\text { first I come to class and I'm like, "Oh what crazy thing are we gonna do today? Let's see what happens." And } \\
\text { then when we're actually doing it I'm just so hyped and I'm so excited and magnets, you know I love magnets. } \\
\text { My magnets, oh those are my babies, I love my magnets. But with magnets and with mirrors and with lenses } \\
\text { it was exciting, it was cool and it was like I knew I was gonna leave with something that was gonna blow } \\
\text { my mind. }\end{array}$ \\
\hline Group work & $\begin{array}{l}\text { With this class I learned how to study with groups. Before, I tend to study by myself, 'cause I get distracted easily } \\
\text { so I think studying for myself actually hurt me because I wasn't able to confirm something with someone else } \\
\text { who might know something that I don't. }\end{array}$ \\
\hline Community & $\begin{array}{l}\text { I knew that if I had a question I could just throw my hand up and even just yell, what is this, and everyone would } \\
\text { have a comment. It felt like a discussion, it was like a sense of family, so it was easier to learn in that way too. } \\
\text { If I have a problem, everyone's going to help me. Everyone's having the same issues, and everyone's at the } \\
\text { same level, we're all going together, so it was just-it really didn't feel like studying to me, which is why I had } \\
\text { such a-which is why I talked to you guys about it so much because it's such a surprising thing. I've never } \\
\text { really felt that before. }\end{array}$ \\
\hline Confidence & $\begin{array}{l}\text { And to fully understand how things work is awesome, it's just-it gives you this power that you didn't know you } \\
\text { had, like this confidence. Because you're just like-I was like, if I could survive this class, I can survive } \\
\text { anything. }\end{array}$ \\
\hline Epistemology & $\begin{array}{l}\text { In our class, this class, we have to figure out the equation ourselves so we have an experience to say, "Oh, } \\
\text { I figured out force equals ILB because I did it myself." I'd say the main thing to learn is just references. } \\
\text { References-it's experience with the topic. Sometimes if they tell you something in class, in any class, they } \\
\text { tell you something and you just believe it because you're being told, "Okay, this is this." But in this class, } \\
\text { you're making it yourself so I guess it's more credible and it's also easier to learn because you have something } \\
\text { to refer back to. }\end{array}$ \\
\hline Problem solving & $\begin{array}{l}\text { If I would have lived back in that time, if it were up to me, we probably wouldn't have the things that we have } \\
\text { because I didn't think as abstract and I wasn't forced to put the pieces together and problem solve, pick out a } \\
\text { problem and try and solve for it. Identifying something and saying, this is what I want for it now let's go about } \\
\text { it and see how we can try and figure that out. That is problem solving, I guess you could say, mentality. }\end{array}$ \\
\hline
\end{tabular}

structure a learning environment, there is often little if any discussion of the intentionality behind it. For example, Engle and Conant [96] offer a set of principles for fostering disciplinary engagement. But there is little discussion of why we should be fostering disciplinary engagement in our students in the first place. Without this filter of intentionality, it is hard to know what theoretical frameworks to adopt, what approaches to explore and implement, and what are the appropriate instructional "moves" in the classroom. We suggest that if we are to make better connections between education theory and classroom implementation, both researchers and implementers need to articulate their underlying intentionalities more explicitly.

Consider, for example, why our cognitive perspective on learning is focused on representation? It is because representation is arguably one of the key features of what makes physics so powerful as a way of thinking about the world. 
TABLE VI. CLASS results.

\begin{tabular}{lcccc}
\hline \hline Category & Pre \% Favorable & Post \% Favorable & \% Gain & Effect size \\
\hline Overall $^{2}$ Personal interest $^{\mathrm{b}}$ & 60.9 & 77.5 & $+16.6^{\mathrm{a}}$ & 1.06 \\
Real world connection $^{\mathrm{d}}$ & 60.3 & 80.9 & $+20.6^{\mathrm{c}}$ & 0.85 \\
Sense making or effort $^{\mathrm{d}}$ & 78.4 & 91.3 & $+12.9^{\mathrm{c}}$ & 0.48 \\
\hline \hline
\end{tabular}

${ }^{\mathrm{a} O v e r a l l ~ C L A S S ~ g a i n ~ s i g n i f i c a n t ~} p<0.001$ (two-tailed $t$ test).

${ }^{\mathrm{b}}$ Category with largest gain, far outstripping others.

${ }^{\mathrm{c}}$ Gain in every subcategory significant at $p<0.05$ (two-tailed $t$ test).

${ }^{\mathrm{d}}$ Categories with lowest gain-likely because they started out highest in pretest.

This is aligned with our first intentionality: students doing physics like physicists. In turn, why did we pick embodied cognition over Anderson's ACT-R theory of cognition [97] or any other theoretical framework? The answer is because it is aligned with our second intentionality. Embodied cognition is practically implementable in the classroom and it is innately human-centered; it gets at the sociallyconstructed nature of meaning. It allows students to (quite literally) experience physics through their bodies [31,32]. Recognizing that communication through representations is a mutual dance of negotiated meaning [37], we do not find ourselves asking questions like "why are students so ignorant that they can't understand our clear explanations?" As teachers we are continuously making space (and time) for that negotiation process to happen.

Consider another case of formative assessment: There are a multitude of ways in which people implement the theoretical idea of formative assessment in their classroom. But our approach is specific to our intentionalities: allowing multiple iterations is exactly how science works and allowing multiple iterations helps students to learn with the understanding that they are not being punished for being wrong, but have the opportunity to improve and get it right. This speaks directly to students' motivation and sense of empowerment over their learning.

\section{B. How theoretical approaches influence activity design and classroom moves}

The theoretical perspectives we have discussed guide us in the design of the activities and how we structure the course. Our perspective on the process by which physicists build their knowledge determines the kinds of activities in which students engage, when they engage in them, and how we assess them. In the paper we have shown examples of such activities and what students do when they work on those. The purpose of having a clearly articulated epistemological structure is so that students know where ideas come from.

The ISLE approach changes the epistemological role of experiments in learning physics-there are no demos or verification labs. Experiments (performed by the instructor or the students) serve one of the three roles:
1. Observational experiments (a pattern that needs explaining) help students devise models, explanations, and relations.

2. Testing experiments help students test newly developed models or explanations (not their intuition).

3. Application experiments help students combine several tested ideas to solve a practical problem, giving students the pleasure of seeing their nascent physics knowledge at work in the real world.

The ISLE approach changes the role of the textbook (or lecture-type videos) in learning-instead of being the authority from which students learn the ideas, these resources become a learning companion to consult after having an experience with the phenomenon and attempting to collaboratively construct and test explanations.

If we want students to construct knowledge by thinking like physicists and be empowered by this process, they need to become part of a learning community. Students work in groups and are equipped with whiteboards, which allow not only for continuous communication between group members and other groups, but when shared with the whole class, contribute to growth and functioning of the whole learning community.

As we have developed and implemented the ISLE approach and watched others implementing it, we have observed new challenges emerging. For example, we have seen that the approach of learning physics by doing physics by itself does not motivate all students. We want students to see the relevance of physics to their daily lives, but it can be hard for them when they are lost in the technical details of drawing force diagrams. That is why we incorporated the idea of need to know [83]. Need to know directly connects with student empowerment and well being in our classroom. When we discover new pedagogical ideas that align with our intentionalities we readily adopt and adapt them.

The theoretical perspectives we adopt directly influence the moves we make while in the classroom and we know why we are doing it because our intentionalities are clearly articulated. As the ISLE approach focuses on students developing habits of mind not finding the right answers, it transforms how we, as teachers, respond to student answers, questions, and comments. In addition to thinking about whether a student is right or wrong and what 
difficulty she or he is having, the ISLE approach switches the focus from correctness to the reasoning process. For example, when a student says that liquids dry because air absorbs moisture, the instructor asks "what experiment can we do to test this idea?" When a student says "I think the ball will curve when it exits the ring," the instructor asks "What hypothesis are you basing this prediction on?" When a student says "I'm stuck and I don't know what to do," the instructor suggests a representational tool like "try drawing an energy bar chart to represent the process." When students use fancy words to describe a phenomenon they are observing the instructor asks "Can you describe it using simple words rather than technical terms?"

\section{Challenges to implementation and future directions}

In this paper we have examined the ISLE approach from two intentionalties, to multiple theoretical perspectives, to classroom implementation. In Sec. IV we showed an example of a successful implementation of the ISLE approach. However, we have also encountered dissatisfaction from students who, for the first time in their life, were being asked to think for themselves instead of being told what to think. This dissatisfaction is consistent with the finding of a recent study by Deslauriers et al., who showed that while students learn more through interactive approaches, they think that they learn less, and they are less satisfied with their learning [98]. Not only do students experience difficulties with the ISLE approach; the mental shift assumed by the intentionalities of the ISLE approach challenges the traditional beliefs of instructors. We have developed activities and materials but we have yet to find ways to help instructors feel confident that they are able to help their students learn to reason and develop physics identity without sacrificing formal knowledge of the physics content. In addition, these fundamental changes to the learning process seem intimidating and risky because of student evaluations. These are legitimate concerns and our future work is focusing on addressing them.

In this paper we have provided one possible answer to the big question "what is the purpose of teaching physics?" (Our answer: We want to empower students with the thinking skills of physicists so that they are able to learn about the physical world both in our course and in their future careers.) Stemming from these intentionalities, we have presented multiple overlapping perspectives that can enable us to achieve that overarching purpose. We hope that it will inspire readers to think more deeply about the intentionalities that underpin their teaching practice.

\section{ACKNOWLEDGMENTS}

We thank Cedric Linder for reading and editing our manuscript and Yuhfen Lin for conducting the interviews. We wish to thank the three reviewers for challenging us to formulate our ideas better and our paper is much improved because of it. This work is supported by NSF Grant No. DUE-1726249. Viewpoints expressed here are those of the authors and do not reflect the views of NSF.
[1] M. C. Wittmann, R. N. Steinberg, and E. F. Redish, Making sense of how students make sense of mechanical waves, Phys. Teach. 37, 15 (1999).

[2] https://youtu.be/XUPHgm9dLIE.

[3] J. Airey and C. Linder, Social semiotics in university physics education, in Multiple Representations in Physics Education, edited by D.F. Treagust, R. Duit, and H. E. Fisher (Springer Nature, Cham, Switzerland, 2017), Chap. 5, pp. 95-122.

[4] E. Etkina and A. Van Heuvelen, Investigative science learning environment-A science process approach to learning physics, in Research-Based Reform of University Physics, edited by E. F. Redish and P. J. Cooney (2007), Vol. 1, https://compadre.org/per/per_reviews/volume1 .cfm\#V1I1A1.

[5] C. J. B. Macmillan and J. W. Garrison, A Logical Theory of Teaching: Erotetics and Intentionality (Kluwer Academic Publishers, Dordrecht, 1988).

[6] P. Cobb, Putting philosophy to work, in Second Handbook of Research on Mathematics Teaching and Learning, edited by F. K. Lester, Jr. (Information Age Publishing, Charlotte, NC, 2007), pp. 3-38.
[7] N. Postman and C. Weingartner, Teaching as a Subversive Activity (Delacorte Press, New York, 1969).

[8] M. McLuhan, The medium is the message, in Media and Cultural Studies, revised ed., edited by M. G. Durham and D. M. Kellner (Blackwell, Malden, MA, 2006), pp. 107-116.

[9] J. S. Brown, A. Collins, and P. Duguid, Situated cognition and the culture of learning, Educ. Res. 18, 32 (1989).

[10] S. Freeman, S. L. Eddy, M. McDonough, M. K. Smith, N. Okoroafor, H. Jordt, and M. P. Wenderoth, Active learning increases student performance in science, engineering, and mathematics, Proc. Natl. Acad. Sci. U.S.A. 111, 8410 (2014).

[11] C. A. Chinn and B. A. Malhotra, Epistemologically authentic inquiry in schools: A theoretical framework for evaluating inquiry tasks, Sci. Educ. 86, 175 (2002).

[12] A. Cimpian and S.-J. Leslie, The brilliance trap, Sci. Am. 317, 60 (2017).

[13] A. Collins and W. Ferguson, Epistemic forms and epistemic games: Structures and strategies to guide inquiry, Educ. Psychol. 28, 25 (1993). 
[14] A. Van Heuvelen, Learning to think like a physicist: A review of research-based instructional strategies, Am. J. Phys. 59, 891 (1991).

[15] J. L. Lemke, Teaching all the languages of science: Words, symbols, images, and actions, in La Caixa Conference on Science Education (1998), https://doi.org/10.13140/ 2.1.4022.5608.

[16] B. Latour, Science in Action (Harvard University Press, Cambridge, MA, 1987).

[17] H. R. Maturana, Science and daily life: The ontology of scientific explanations, in Self-Organization Portrait of a Scientific Revolution, edited by W. Krohn, G. Kuppers, and H. Nowotny (Kluwer Academic Publishers, Dordrecht, 1990), Vol. 14, pp. 12-35.

[18] B. Rogoff, E. Matusov, and C. White, Models of teaching and learning: Participation in a community of learners, in Handbook of Education and Human Development, edited by D. R. Olson and N. Torrance (Blackwell, Oxford, UK, 1996), Chap. 18, pp. 388-414.

[19] J. Lave and E. Wenger, Situated Learning: Legitimate Peripheral Participation (Cambridge University Press, Cambridge, England, 1991).

[20] M. B. Hesse, Models and Analogies in Science (University of Notre Dame Press, Notre Dame, IN, 1966).

[21] A. E. Lawson, What does Galileo's discovery of Jupiter's moons tell us about the process of scientific discovery?, Sci. Educ. 11, 1 (2002).

[22] D. Allchin, Lawson's shoehorn, or should the philosophy of science be rated 'x?', Sci. Educ. 12, 315 (2003).

[23] N. J. Nersessian, Maxwell and "the method of physical analogy": Model-based reasoning, generic abstraction, and conceptual change, in Reading Natural Philosophy: Essays in the History and Philosophy of Science and Mathematics, edited by D. B. Malament (Open Court, Chicago and La Salle, IL, 2002), pp. 129-166.

[24] M. Born, Experiment and Theory in Physics (Cambridge University Press, Cambridge, England, 1943).

[25] Open Science Collaboration, Estimating the reproducibility of psychological science, Science 349, 4716 (2015).

[26] K. Popper, The Logic of Scientific Discovery (Hutchinson, London, 1980).

[27] D. Rosengrant, A. Van Heuvelen, and E. Etkina, Do students use and understand free-body diagrams?, Phys. Rev. ST Phys. Educ. Res. 5, 010108 (2009).

[28] B. Rotman, Toward a semiotics of mathematics, Semiotica 72, 1 (1988).

[29] D. T. Brookes and E. Etkina, Using conceptual metaphor and functional grammar to explore how language used in physics affects student learning, Phys. Rev. ST Phys. Educ. Res. 3, 010105 (2007).

[30] D. L. Schwartz, Physical imagery: Kinematic versus dynamic models, Cogn. Psychol. 38, 433 (1999).

[31] A. J. Richards and E. Etkina, Kinaesthetic learning activities and learning about solar cells, Phys. Educ. 48, 578 (2013).

[32] A. R. Daane, L. Wells, and R. E. Scherr, Energy theater, Phys. Teach. 52, 291 (2014).

[33] D. A. Norman, Things that Make us Smart (Diversion Books, New York, NY, 1993).

[34] E. Hutchins, How a cockpit remembers its speeds, Cogn. Sci. 19, 265 (1995).
[35] D. L. Schwartz, T. Martin, and J. Pfaffman, How mathematics propels the development of physical knowledge, J. Cognit. Dev. 6, 65 (2005).

[36] W.-M. Roth and M. K. McGinn, Inscriptions: Toward a theory of representing as social practice, Rev. Educ. Res. 68, 35 (1998).

[37] M. J. Reddy, The conduit metaphor: A case of frame conflict in our language about language, in Metaphor and Thought, 2nd ed., edited by A. Ortony (Cambridge University Press, Cambridge, England, 1993), pp. 164-201.

[38] D. T. Brookes and E. Etkina, "Force," ontology, and language, Phys. Rev. ST Phys. Educ. Res. 5, 010110 (2009).

[39] L. W. Barsalou, Perceptual symbol systems, Behav. Brain Sci. 22, 577 (1999).

[40] G. Lakoff and M. Johnson, Philosophy in the Flesh (Basic Books, New York, NY, 1999), Vol. 4.

[41] L. W. Barsalou, Grounded cognition, Annu. Rev. Psychol. 59, 617 (2008).

[42] E. Sapir, The status of linguistics as a science, in Culture, Language and Personallity, edited by D. B. Mandelbaum (University of California Press, Berkeley and Los Angeles, 1957), pp. 65-77.

[43] B. L. Whorf, The relation of habitual thought and behavior to language, in Language, Thought, and Reality. Selected Writings of Benjamin Lee Whorf, edited by J. B. Carroll (MIT Press, Cambridge, MA, 1956), pp. 134-159.

[44] B. L. Whorf, Science and linguistics, in Language, Thought, and Reality. Selected Writings of Benjamin Lee Whorf, edited by J. B. Carroll (MIT Press, Cambridge, MA, 1956), pp. 207-219.

[45] A. Williams Woolley, C. F. Chabris, A. Pentland, N. Hashmi, and T.W. Malone, Evidence for a collective intelligence factor in the performance of human groups, Science 330, 686 (2010).

[46] M. A. Elliot, Stigmergic collaboration: A theoretical framework for mass collaboration, Ph.D. Thesis, The University of Melbourne, 2007.

[47] J. McGonigal, Why I love bees: A case study in collective intelligence gaming, in The Ecology of Games: Connecting Youth, Games, and Learning, The John D. and Catherine T. MacArthur Foundation Series on Digital Media and Learning, edited by K. Salen Tekinbas (MIT Press, Cambridge, MA, 2008), pp. 199-228.

[48] M. Scardamalia and C. Bereiter, Computer support for knowledge-building communities, J. Learn. Sci. 3, 265 (1994).

[49] D. S. Wilson, E. Ostrom, and M. E. Cox, Generalizing the core design principles for the efficacy of groups, J. Econ. Behav. Organ. 90S, S21 (2013).

[50] K. Bielaczyc and A. Collins, Learning communities in classrooms: A reconceptualization of educational practice, in Instructional Design Theories and Models, Vol. II, edited by C. M. Reigeluth (Lawrence Erlbaum Associates, Mahwah, NJ, 1999), Chap. 12, pp. 269-292.

[51] I. Esmonde, Mathematics learning in groups: Analyzing equity in two cooperative activity structures, J. Learn. Sci. 18, 247 (2009).

[52] R. H. Moos, Social contexts: Transcending their power and their fragility, Am. J. Commun. Psychol. 31, 1 (2003). 
[53] A. Calabrese Barton, Teaching Science for Social Justice (Teachers College Press, New York, NY, 2003).

[54] H. B. Carlone, The cultural production of science in reform-based physics: Girls' access, participation, and resistance, J. Res. Sci. Teach. 41, 392 (2004).

[55] H. B. Carlone and A. Johnson, Understanding the science experiences of successful women of color: Science identity as an analytic lens, J. Res. Sci. Teach. 44, 1187 (2007).

[56] K. Tobin, Fostering science learning in diverse urban settings, AIP Conf. Proc. 1064, 50 (2008).

[57] C. Ames, Classrooms: Goals, structures, and student motivation, J. Educ. Psychol. 84, 261 (1992).

[58] J. M. Saul, 2017 AAPT Summer Meeting, Cincinatti (2017), https://www.aapt.org/docdirectory/meetingpresentations/ SM17/Parachute\%20Courses.pdf.

[59] E. Seymour and N. M. Hewitt, Talking About Leaving: Why Undergraduates Leave The Sciences, 1st ed. (Westview Press, Boulder, CO, 1997).

[60] P. Jones, Situating universal design architecture: Designing with whom?, Disability and rehabilitation 36, 1369 (2014).

[61] CAST, Universal Design for Learning Guidelines, version 1.0, Tech. Rep. (Center for Applied Special Technology, Wakefield, MA, 2008).

[62] S. S. Scott, J. M. McGuire, and T. E. Foley, Universal design for instruction: A framework for anticipating and responding to disability and other diverse learning needs in the college classroom, Equity Excellence Educ. 36, 40 (2003).

[63] J. W. Valle and D. J. Connor, Rethinking Disability: A Disability Studies Approach to Inclusive Practices (McGraw-Hill, New York, 2011).

[64] J. Brophy, Conceptualizing student motivation, Educ. Psychol. 18, 200 (1983).

[65] C. S. Dweck and E. L. Leggett, A social-cognitive approach to motivation and personality, Psychol. Rev. 95, 256 (1988).

[66] D. S. Yeager and C.S. Dweck, Mindsets that promote resilience: When students believe that personal characteristics can be developed, Educ. Psychol. 47, 302 (2012).

[67] D. I. Cordova and M. R. Lepper, Intrinsic motivation and the process of learning: Beneficial effects of contextualization, personalization, and choice, J. Educ. Psychol. 88, 715 (1996).

[68] M. V. Covington and C.L. Omelich, Task-oriented versus competitive learning structures: Motivational and performance consequences, J. Educ. Psychol. 76, 1038 (1984).

[69] E. Etkina, D. Brookes, G. Planinsic, and A. Van Heuvelen, Active Learning Guide for College Physics: Explore and Apply, 2nd ed. (Pearson, San Francisco, CA, 2019).

[70] J. I. Heller and F. Reif, Prescribing effective human problem-solving processes: Problem description in physics, Cognit. Instr. 1, 177 (1984).

[71] L. C. McDermott and P. S. Shaffer, Tutorials in Introductory Physics (Prentice Hall, New York, 1998).

[72] E. Etkina, Millikan award lecture: Students of physicsListeners, observers, or collaborative participants in physics scientific practices?, Am. J. Phys. 83, 669 (2015).

[73] D. T. Brookes and Y. Lin, Designing a physics learning environment: A holistic approach, AIP Conf. Proc. 1413, 131 (2012).
[74] Grant P. Wiggins and Jay McTighe, Understanding by Design, 2nd ed. (ASCD, Virginia, 2005).

[75] E. Etkina, G. Planinsic, and A. Van Heuvelen, College Physics: Explore and Apply, 2nd ed. (Pearson, San Francisco, CA, 2019).

[76] E. Etkina, D. Brookes, G. Planinsic, and A. Van Heuvelen, Instructor's Guide for College Physics: Explore and Apply, 2nd ed. (Pearson, San Francisco, CA, 2019).

[77] http://pum.islephysics.net/, http://videos.islephysics.net/, https://sites.google.com/site/scientificabilities/rubrics.

[78] D. L. Schwartz and J. D. Bransford, A time for telling, Cognit. Instr. 16, 475 (1998).

[79] E. Etkina, A. Van Heuvelen, S. White-Brahmia, D. T. Brookes, M. Gentile, S. Murthy, D. Rosengrant, and A. Warren, Scientific abilities and their assessment, Phys. Rev. ST Phys. Educ. Res. 2, 020103 (2006).

[80] E. Etkina, A. Karelina, and M. Ruibal-Villasenor, How long does it take? a study of student acquisition of scientific abilities, Phys. Rev. ST Phys. Educ. Res. 4, 020108 (2008).

[81] E. Etkina, K. Gibbons, B. L. Holton, and G. K. Horton, Lessons learned: A case study of an integrated way of teaching introductory physics to at-risk students at Rutgers University, Am. J. Phys. 67, 810 (1999).

[82] S. Brahmia and E. Etkina, Switching students on to science, J. Coll. Sci. Teach. 31, 183 (2001), https://eric .ed.gov/?id=EJ646174.

[83] M. S. Knowles, The Modern Practice of Adult Education (Cambridge Adult Education, Englewood Cliffs, NJ, 1980).

[84] https://www.youtube.com/watch?v=OTcdutIcEJ4.

[85] E. Etkina, A. Karelina, M. Ruibal-Villasenor, D. Rosengrant, R. Jordan, and C. E. Hmelo-Silver, Design and reflection help students develop scientific abilities: Learning in introductory physics laboratories, J. Learn. Sci. 19, 54 (2010).

[86] D. Demaree and Y. Lin, Assessing ISLE labs as an enhancement to traditional large-lecture courses at the Ohio State University, AIP Conf. Proc. 818, 105 (2006).

[87] P. Black and D. Wiliam, Assessment and classroom learning, Assess. Educ. 5, 7 (1998).

[88] https://sites.google.com/site/scientificabilities/rubrics.

[89] D. T. Brookes and E. Etkina, In search of alignment: Matching learning goals and class assessments, AIP Conf. Proc. 1413, 11 (2012).

[90] A. Warren, Impact of teaching students to use evaluation strategies, Phys. Rev. ST Phys. Educ. Res. 6, 020103 (2010).

[91] D. T. Brookes and Y. Lin, Structuring classroom discourse using formative assessment rubrics, AIP Conf. Proc. 1289, 5 (2010).

[92] Y. Lin and D. T. Brookes, Using collaborative group exams to investigate students' ability to learn, AIP Conf. Proc. 1513, 254 (2013).

[93] W. K. Adams, K. K. Perkins, N. S. Podolefsky, M. Dubson, N. D. Finkelstein, and C. E. Wieman, New instrument for measuring student beliefs about physics and learning physics: The Colorado Learning Attitudes about Science Survey, Phys. Rev. ST Phys. Educ. Res. 2, 010101 (2006).

[94] E. Brewe, A. Traxler, J. de la Garza, and L. H. Kramer, Extending positive CLASS results across multiple instructors and multiple classes of Modeling Instruction, Phys. Rev. ST Phys. Educ. Res. 9, 020116 (2013). 
[95] I. V. S. Mullis, M. O. Martin, P. Foy, and M. Hooper, TIMSS Advanced 2015 International Results in Advanced Mathematics and Physics, Tech. Rep. (Lynch School of Education, Boston College, Boston, 2015).

[96] R. A. Engle and F. R. Conant, Guiding principles for fostering productive disciplinary engagement: Explaining an emergent argument in a community of learners classroom, Cognit. Instr. 20, 399 (2002).
[97] J. R. Anderson, Human symbol manipulation within an integrated cognitive architecture, Cogn. Sci. 29, 313 (2005).

[98] L. Deslauriers, L. S. McCarty, K. Miller, K. Callaghan, and G. Kestin, Measuring actual learning versus feeling of learning in response to being actively engaged in the classroom, Proc. Natl. Acad. Sci. U.S.A. 116, 19251 (2019). 